\title{
El campamento minero Chuquicamata-2 y la explotación cuprífera prehispánica en el Desierto de Atacama
}

\author{
Lautaro Núñez A., ${ }^{1}$ Carolina Agüero P., ${ }^{1}$ Bárbara Cases C. ${ }^{2}$ Y Patricio de Souza H. ${ }^{2}$
}

\begin{abstract}
RESUMEN
Se presentan los primeros estudios del campamento minero Chu-2 con evidencias de explotación cuprífera previa al dominio inca, utilizado desde fines del Período Formativo, hasta el Intermedio Tardio, constituyendo el primer asentamiento de este tipo reconocido en el sector de Chuquicamata-Tomic. La relación de tareas mineras extractivas, asociadas a alfarería de las cuencas del Loa y Atacama, Altiplano Meridional, Valles Occidentales de Tarapacá, y rutas caravaneras, posicionan a Chu-2 como un sitio clave para entender las labores mineras fuera de los valles, en un medio alejado de los recursos de agua, dando cuenta del objetivo minero vinculado a afloramientos de atacamita, cobre nativo y de color, que incluían tanto la materia prima para fundido, como para aplicaciones ritualísticas y de ornato. Se propone que representa a grupos mineros provenientes de asentamientos estables no como eventos aislados ni espontáneos, sino al interior de políticas expansivas de explotación de las poblaciones del río Loa Medio-Superior y de San Pedro de Atacama.
\end{abstract}

Palabras claves: asentamientos - minería prehispánica desierto de Atacama.

\section{ABSTRACT}

This work gives the results of the first studies carried out in mining camp Chu-2, with evidence of copper exploitation activities previous to Inca rule. This site is the first of its kind in the Chuquicamata-Tomic area, and was occupied from close to the end of the Formative Period, until the Late Intermediate. The relationship between extractive mining activities, associated to ceramics from the southern Altiplano, the occidental valleys of Tarapaca, the Loa and Atacama basins, and their caravanning routes, position Chu-2 as a site that is a key to the understanding of mining labour outside the valleys, in environments far from any water resource. This enables an account of the purposes of Atacamita, and native and coloured copper mining, from the uses of the material that was needed for smelting and those used in

1 Instituto de Investigaciones Arqueológicas y Museo R. P. Gustavo Le Paige s. j., Universidad Católica del Norte, San Pedro de Atacama. Email: lautanunez@netline.cl; maguero@ucn.cl

2 Programa Magíster Universidad Católica del Norte-Universidad de Tarapacá.Email: bcases@ucn.cl; pdesouza@ucn.cl ornamental and ritual applications. We propose that the site does not represent an isolated or spontaneous event, but the presence of mining groups that came from stable settlements, suggesting expansive exploitation politics that stemmed from the middle and higher Loa regions and San Pedro de Atacama.

Key words: settlements - pre-Hispanic mining - Atacama Desert.

Recibido: agosto 2003. Manuscrito revisado aceptado: enero 2004

\section{Introducción}

La creciente identificación de implementos metálicos, más de estatus que domésticos, a lo largo de las secuencias regionales del área y su ocurrencia en territorios carentes de recursos, junto al desarrollo de criterios metodológicos adecuados, han sustentado la idea de que en el pasado existió un intenso tráfico de metales (A. R. González 1979; Lechtman 1980 y 1997; L. R. González 2001; Núñez 1987).

Hace ya dos décadas, a partir de la distribución de los recursos mineros andinos, Lechtman (1980) propuso al Area Centro Sur y parte de la Meridional, como uno de los dos centros metalúrgicos prehispánicos con innovaciones tecnológicas de repercusión interregional. En efecto, los tempranos registros de la Fase Tilocalar (1190 AC-470 AC) en el norte de Chile demuestran que las tradiciones minero-metalúrgicas de la Circumpuna de Atacama y Altiplano Meridional son independientes, y provienen de experiencias formativas tempranas con especializaciones de oficios en contextos pastoriles surandinos (Núñez 1994; Ponce 1970). Su patrón de registro se relaciona con un tráfico de larga distancia, a juzgar por la presencia de turquesa y lapislázuli en los Andes Centrales y Septentrionales, atribuida a interacciones con el desierto chileno (Marcos y Norton 1979 Ms: 9; Petersen 1970: 13).

Posteriormente, con la hegemonía Tiwanaku, la actividad minero-metalúrgica local alcanzó un alto 
grado de perfeccionamiento estilístico y acrecentó la producción de objetos de uso doméstico (cucharas, pinzas, cinceles, mazas), de ornamentos (cintillos, vasos libatorios, cascabeles, campanillas) y bienes de prestigio (hachas), confeccionados en cobre, oro, plata, estaño y plomo, además de sus respectivas aleaciones (Tarragó y L. R. González 1998; Lechtman 1984; Lechtman y A. R. González 1991; Núñez 1994).

Precisamente, el campamento Chuquicamata-2 (Chu-2) datado por $\mathrm{C}^{14}$ en 780-1020 DC, sería parte de un régimen laboral local instalado en una de las áreas más altamente mineralizadas del norte de Chile durante los últimos eventos del flujo Tiwanaku. En este sentido, las labores mineras requieren del apoyo de los recursos agroganaderos del río Loa, ya que los sitios de extracción están alejados de los valles en un medio de máxima aridez. Se trata de afloramientos cupríferos expuestos, en cuyo entorno se establecieron campamentos de labor a lo largo del cinturón de cobre (Sutulov 1978) por lo menos desde los 700 a 1400 DC, antes de las ocupaciones incas y españolas (Núñez 1998 Ms y 1999 Ms).

Posteriormente, las actividades extractivas se reflejan en el curso medio del río Loa, a través del cementerio Chunchurí o Dupont, datado a los 1390 DC, con evidencias vinculadas con el distrito cuprífero aledaño. Sólo en tres enterramientos (uno colectivo datado) excavados por el primer autor (Núñez 1968) se detectaron varias campanitas plegadas, placas de cobre y pequeñas láminas de oro. La excavación allí realizada previamente por Uhle (1913), a juzgar por el inventario inédito, habría recuperado cerca de 204 cuerpos agrupados en un número desconocido de tumbas colectivas e individuales. De este contexto provienen campanitas de cobre y oro, una plancheta de oro con cabeza de felino, placas rectangulares, discos, tubos, hojas de hachas, una placa de cobre en forma de ' $\mathrm{T}$ ' $\mathrm{y}$ fragmentos de óxido de fundición. Como esta población se emplazaba en Calama junto al río, es probable que grupos de mineros especializados de este u otro sitio del Loa acudían antes de los incas a las minas de Chuquicamata.

Es muy posible que las labores de fundición se realizaran junto a los bosques de Calama, puesto que recientemente se han registrado restos de guayras, correspondientes a fragmentos de cerá- mica con escoria adherida, asociados a mineral de cobre molido, en tres colinas al este de aquella ciudad. Se trata de pequeñas fundiciones de cobre apoyadas por la acción eólica, asociadas precisamente a la cerámica Dupont (Núñez 2001 Ms).

En el Loa inferior, Latcham (1938) también señaló para Quillagua una alta presencia de objetos metálicos en ofrendas funerarias, ratificado por otros objetos similares con fechas tempranas desde $\operatorname{los} 600 \mathrm{AC}$ en formaciones tumulares de Quillagua-89, con evidencias de placas y cuentas tubulares de cobre martillado, al 1000 DC, esta vez en el Cementerio Oriente (Qui-01) con registro de brazalete y placa de metal (Agüero et al. 1997, 1999 y 2001). De manera contemporánea al sitio anterior, en la aldea La Capilla, se constataron 18 fragmentos de moldes para fundir barras de cobre (Cervellino y Téllez 1980). En general, las lingoteras permitieron la circulación de barras como "preformas", que luego eran martilladas y/o refundidas para lograr una función específica. La ausencia de moldes con diseños definidos sugiere más bien una acumulación excedentaria interregional de matrices metálicas o lingotes, trasladadas en una amplia red de tráfico regional, y que se transformaban en múltiples objetos refundidos de acuerdo a los requerimientos del grupo receptor. Se puede sostener, entonces, que los habitantes del río Loa, oasis atacameños y aquellos de la costa del desierto de Atacama organizaban grupos mineros en los distritos con mayores recursos desde antes de los incas.

Durante la expansión inca se amplió la escala de las labores mineras por sobre la producción agropecuaria, sumándose a las instalaciones de Cerro Verde y otras del Loa Superior y Medio, la explotación de más distritos mineros que ahora se conocen como Chuquicamata, El Abra y Tomic, con similares componentes culturales, bajo el control directo de la administración incaica, pactada con los curacas locales (Uribe y Carrasco 1999; Núñez 1999; Salazar et al. 2001). Por otra parte, las palas y vasijas de la mayoría de los sitios mineros incas se corresponden con logros tecnológicos del Período Intermedio Tardío: tipos cerámicos Turi alisados, revestidos, Dupont, Ayquina y S. P. Rojo Violáceo, es decir, aquellos que integran el componente Loa-San Pedro (Uribe 1997 y 1999). Esto significa que los bienes de producción y de uso ya eran suficientemente idóneos durante la aplicación de la política de ex- 
pansión minera incaica, manteniéndose las tecnologías previas, en un territorio integrado por sus valores más mineros que agrarios, a través de una intervención inca más directa de lo que se había supuesto (Uribe y Carrasco 1999; Núñez 1999). En este escenario, los distritos cupríferos, incluyendo turquesa, crisocola u otras rocas preciosas de la Puna de Atacama, fueron relevantes en la secuencia regional, reflejándose en los contextos funerarios. No obstante, la naturaleza de los campamentos de labores incas y preincas, sólo recientemente se han descrito sus primeras instalaciones identificadas junto a las minas específicas (Núñez 1999; Salazar et al. 2001).

\section{Ocupación humana del distrito minero Chuquicamata}

Los estudios de impacto ambiental arqueológico han permitido explorar áreas con recursos mineros, abriendo insospechadas expectativas para identificar instalaciones y tráfico minero insertos en locis extractivos óptimos, alejados de las modalidades domésticas presentes en los núcleos aldeanos (Núñez 1999). En esta oportunidad se sintetiza una investigación inserta en el "Programa de Protección y Educación de los Valores Arqueológicos de la Segunda Región", que desarrolló la ex División Radomiro Tomic de CODELCO, en la que fue posible estudiar en detalle el campamento Chu-2, que presenta depósitos correlacionados con redes minero-extractivas anteriores a la ocupación inca (Figura 1).

Los sitios localizados en los distritos mineros de Chuquicamata, Tomic y El Abra documentan un sistema de campamentos extractivos relacionados entre sí, situados en espacios de alto rendimiento minero-metalúrgico, y que comprende una secuencia ocupacional, cuya profundidad cronológica sugiere ocupaciones formativas hasta incaicas, coloniales, incluyendo el siglo XX, con intensa actividad minera. La presencia de martillos, minerales de cobre triturados, tiestos, contenedores de agua y socavones, indican acciones especializadas en labores extractivas, con actividades asociadas de consumo, preparación de cargas, mantención de caravanas, descanso, traslado de gentes, recursos y minerales seleccionados.

De acuerdo al total de los sitios registrados, se puede afirmar que las ocupaciones se insertaron en un medio alejado de los recursos de agua, dando cuenta de un objetivo minero inequívoco, asociado a ricos afloramientos de atacamita superficiales y cobre nativo, que incluían tanto la mate-
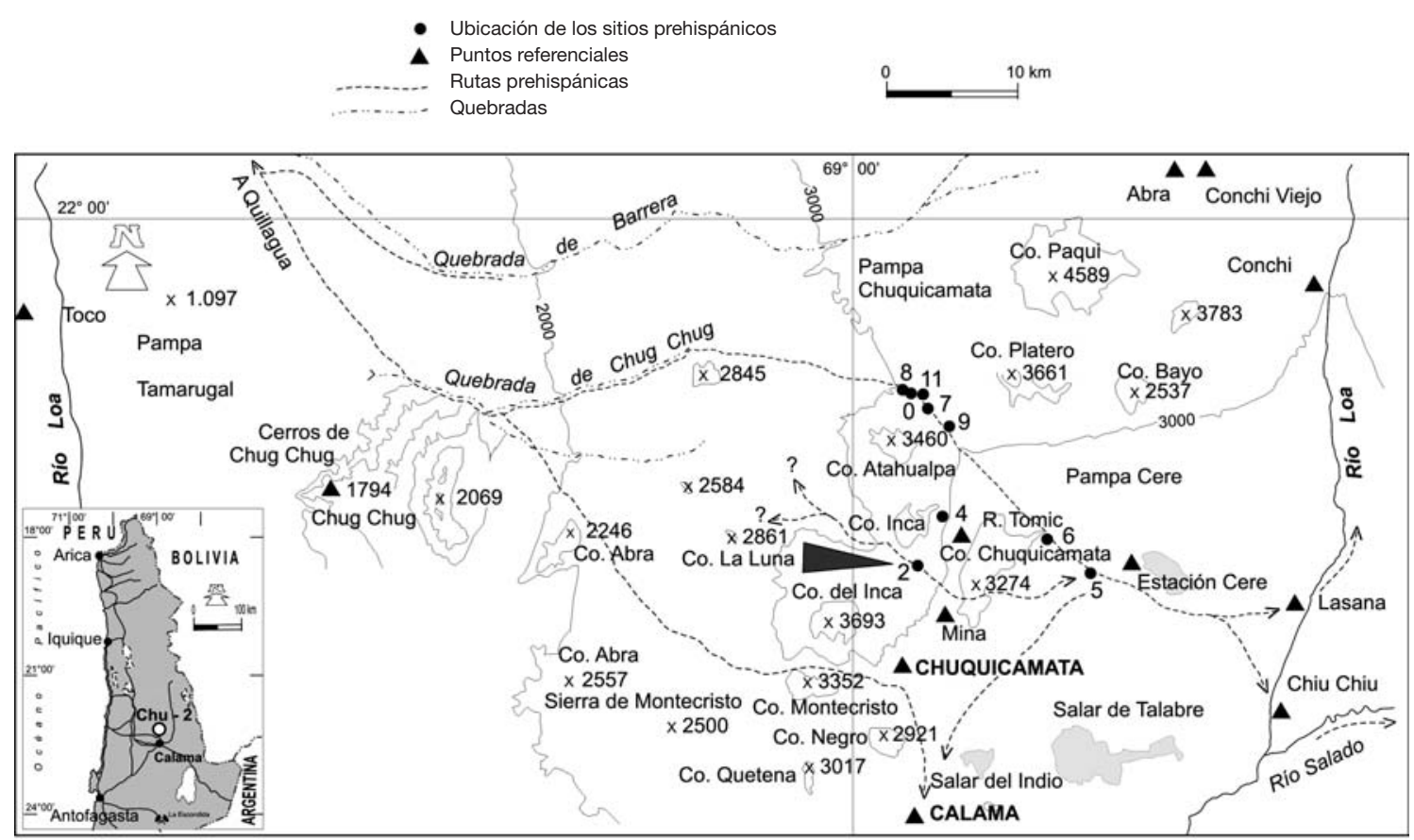

Figura 1. Mapa de ubicación del sitio Chu-2 en el distrito arqueológico de Chuquicamata-Tomic, y las principales rutas prehispánicas de interacción regional. 
ria prima para fundido (atacamita) como para aplicaciones ritualísticas y de ornato (p.e., crisocola). Es decir, representan a colonos mineros provenientes de las aldeas estables del río Loa Medio-Superior y cuenca de San Pedro de Atacama no como eventos aislados ni espontáneos, sino al interior de políticas de dominio por parte de los curacas locales, y luego bajo el régimen incaico.

Es posible que durante tiempos formativos estos distritos mineralizados ya hayan sido ocupados a juzgar por la cerámica negra pulida de paredes delgadas (Sequitor) en torno a la aguada cercana a la mina de El Abra (Ab-33) (Núñez 1998 Ms y 1999; Salazar et al. 2001). Posteriormente, otros grupos de tareas específicas se desplazarían por una red de rutas caravaneras que tienen un punto de encuentro en el salar de Cere. Desde aquí, se introduce un ramal a Chu-5 que, en su rol de paskana principal, fue ocupado desde el Período Intermedio Tardío al contacto colonial. El otro ramal se introduce por un portezuelo hacia Chu-10 y Chu-2, a través de la serranía de Chuquicamata. Las rutas preincaicas y sus rituales en los sitios Chu-7, Chu-8 y Chu-9 indicarían que los rumbos caravaneros sobrepasaron el área mineralizada de la serranía de ChuquicamataTomic, orientándose a la ruta preinca que une Calama con la vertiente de quebrada Chug Chug, enfrentada a los geoglifos del camino a Chuquicamata, cerro de Chug Chug, vertiente de quebrada Chug Chug (Briones et al. 1997 Ms) y oeste Chuquicamata hasta alcanzar la desembocadura del Loa por Quillagua, incluyendo allí el desvío a los Valles Occidentales de la I Región (Tabla 1).

Por todo lo anterior, se admite que durante el Período Intermedio Tardío se desarrolló un sistema de ocupación minero-extractivo, con campamentos y rutas procedentes de las aldeas permanentes, preferentemente del río Loa Medio y Superior, orientados a la explotación de los distritos de Chuquicamata-Tomic y El Abra, con conexiones con las tierras bajas y el litoral desde etapas formativas e intermedias tardías, hasta incluir contactos incas, hispánicos y arrieros o pirquineros aislados de tiempos subactuales.

Precisamente, las excavaciones en el campamento Chu-2 se han privilegiado por constituir hasta ahora el único sitio que daría cuenta de actividades humanas en el desierto extremo, vinculado con actividades mineras y tráfico caravanero preincaico, que permitiría explicar la integración de los asentamientos del río Loa Medio y Superior con áreas de recursos mineros y costeros a nivel regional.

Se propone que el contexto minero-extractivo llamado "Hombre de Cobre", registrado en el siglo pasado en una mina de Chuquicamata (Bird 1977 y 1979), corresponde precisamente a un evento contemporáneo con el campamento Chu-2. Se trata de un joven polifracturado fallecido en plenas labores extractivas, proveniente de un socavón donde cumplía labores en una serranía inhóspita (2600-2800 m.snm), sin recursos locales de subsistencia, a no más de $21 \mathrm{~km}$ del río Loa (sector Calama). Presenta un cuerpo bien conservado y corpulento con manos fuertes y uñas desgastadas por las labores extremas, distantes de su núcleo aldeano, como parte de una colonia o fuerza de tarea trasladada para ejecutar actividades mineras extractivas. Usa un trenzado compuesto por tres coletas amarradas a cada lado y tobilleras en los pies. Está cubierto sólo por un cobertor púbico tejido en faz de urdimbre sujeto a la cintura por una faja. Además, fue hallado junto a cestos un capacho de cuero, grandes martillos líticos y una pala con mango de madera atado con cuero. La pala se ajusta a las lajas plaquiformes confirmándose el doble patrón de uso tanto agrario como minero, tal como se había propuesto para Caspana (Uribe y Carrasco 1999). Los martillos presentan mangos completos, es decir, con varas tensionadas con cueros que, a su vez, ajustan el percutor de roca, asemejándose a los usados durante la etapa incaica en la cercana mina El Abra, demostrando de paso que la tradición minera extractiva fue ya especializada antes del Período Intermedio Tardío y, obviamente, antes de los incas. De tal modo, los incas no habrían aportado innovaciones tecnológicas para el trabajo minero (Núñez 1999). Fuera de dudas, trabajadores con los atributos del "Hombre de Cobre" debieron vivir y trabajar en campamentos, como el que se tratará aquí. Tanto el tipo físico como sus objetos y los sitios asociados, con seguridad señalan que estos mineros especialistas provienen de las poblaciones agroganaderas del río Loa y San Pedro de Atacama, incluso durante el dominio inca.

Se sabe que durante la ocupación inca este territorio fue más proclive a la explotación minera, tal como se ha observado en la actual mina El Abra. 


\begin{tabular}{|c|c|c|c|c|c|}
\hline Sitios & $\begin{array}{l}\text { Coordenadas UTM } \\
\qquad(\mathrm{E} / \mathrm{N})\end{array}$ & Tipo de sitio & Cronología & Descripción & Observaciones \\
\hline Chu-1 & $513.200 / 7.541 .300$ & Instalación minera & $\begin{array}{l}\text { Histórico subactual } \\
\text { (s. XX) }\end{array}$ & $\begin{array}{l}2 \text { recintos de mina } \\
\text { Corina y accesorios }\end{array}$ & $\begin{array}{l}\text { Instalaciones mineras, estructuras y } \\
\text { basural. }\end{array}$ \\
\hline Chu-2 & 509.364 / 7.539.977 & Campamento & Prehispánico & $\begin{array}{l}8 \text { estructuras } 0 \\
\text { recintos pircados }\end{array}$ & $\begin{array}{l}\text { Asentamiento asociado a rutas caravaneras, } \\
\text { con activades intra y extramuro. } \\
\text { Identificación de depósitos subyacentes y } \\
\text { fragmentación cerámica, restos líticos y } \\
\text { orgánicos. }\end{array}$ \\
\hline Chu-3 & $509.370 / 7.543 .406$ & Recinto aislado & $\begin{array}{l}\text { Histórico subactual } \\
(\mathrm{s} . \mathrm{XX})\end{array}$ & $\begin{array}{l}1 \text { estructura o recinto } \\
\text { pircado simple }\end{array}$ & Recinto aislado. \\
\hline Chu-4 & $510.968 / 7.545 .594$ & Campamento & Prehispánico & $\begin{array}{l}19 \text { estructuras o } \\
\text { recintos pircados }\end{array}$ & $\begin{array}{l}\text { Asentamiento con recintos y bodegas, } \\
\text { ausencia de restos culturales superficiales. } \\
\text { El diseño de una estructura trapezoidal } \\
\text { podría sugerir su relación con la ocupación } \\
\text { incaica. }\end{array}$ \\
\hline Chu-5 & $522.832 / 7.541 .935$ & Campamento & $\begin{array}{l}\text { Prehispánico con } \\
\text { reocupaciones }\end{array}$ & $\begin{array}{l}27 \text { estructuras } 0 \\
\text { recintos pircados }\end{array}$ & $\begin{array}{l}\text { Asentamiento con recintos semicirculares } \\
\text { aglomerados asociados a rutas caravaneras } \\
\text { y cerámica del período Intermedio Tardío e } \\
\text { Hispánico colonial. }\end{array}$ \\
\hline Chu-6 & $520.864 / 7.542 .720$ & Campamento & Prehispánico & $\begin{array}{l}4 \text { estructuras o } \\
\text { recintos pircados y } \\
8 \text { depresiones }\end{array}$ & $\begin{array}{l}\text { Asentamiento menor con recintos circulares } \\
\text { y ausencia de restos culturales. }\end{array}$ \\
\hline Chu-7 & 509.083 / 7.552.971 & Estación de tráfico & $\begin{array}{l}\text { Prehispánico (?) } \\
\text { Hispánico } \\
\text { (s. XVII) }\end{array}$ & $\begin{array}{l}2 \text { estructuras o } \\
\text { recintos pircados y } \\
\text { foso relleno }\end{array}$ & $\begin{array}{l}\text { Paskana con posibles restos prehispánicos } \\
\text { y fragmentos de botija colonial, asociado a } \\
\text { rutas orientadas al Pacífico (red Calama- } \\
\text { Quillagua). }\end{array}$ \\
\hline Chu-8 & $507.456 / 7.554 .155$ & Estación de tráfico & $\begin{array}{l}\text { Histórico subactual } \\
\text { (s. XX) }\end{array}$ & $\begin{array}{l}5 \text { estructuras } 0 \\
\text { recintos pircados y } \\
\text { portezuelo con rutas }\end{array}$ & $\begin{array}{l}\text { Paskana asociada a portezuelo y rutas } \\
\text { orientadas al Pacífico (red Calama- } \\
\text { Quillagua). }\end{array}$ \\
\hline Chu-9 & $511.370 / 7.550 .819$ & $\begin{array}{l}\text { Rutas con rituales de } \\
\text { tráfico caravanero }\end{array}$ & Prehispánico & $\begin{array}{l}\text { Rutas asociadas a } \\
\text { ofrendas de partículas } \\
\text { de cobre, cerámica y } \\
\text { marcas de piedras }\end{array}$ & $\begin{array}{l}\text { Senderos del patrón "rastrillo" asociados a } \\
\text { "quiebras" de cerámica del Período } \\
\text { Intermedio Tardío del río Loa, altiplano y } \\
\text { S. P. de Atacama. También cajita de } \\
\text { ofrendas y material lítico. Ruta se orienta } \\
\text { al Loa Medio, a la conexión Calama- } \\
\text { Quillagua-Costa-Valles Tarapaqueños. }\end{array}$ \\
\hline Chu-10 & $507.995 / 7.539 .058$ & Instalación minera & $\begin{array}{l}\text { Histórico subactual } \\
\text { (inicios s. XX) }\end{array}$ & $\begin{array}{l}2 \text { recintos, } 3 \text { piques y } \\
3 \text { canchas empedradas } \\
\text { ("La Salvadora") }\end{array}$ & $\begin{array}{l}\text { Instalaciones mineras, estructuras y labores } \\
\text { junto a la galería semivertical. }\end{array}$ \\
\hline Chu-11 & $508.250 / 7.554 .348$ & Estación de tráfico & Prehispánico & $\begin{array}{l}1 \text { recinto estructurado } \\
\text { con depresiones } \\
\text { asociadas }\end{array}$ & $\begin{array}{l}\text { Paskana con restos de mineral de cobre no } \\
\text { triturado y bastante cerámica loína del } \\
\text { Período Intermedio Tardío. }\end{array}$ \\
\hline
\end{tabular}

Tabla 1. Listado y principales características de los sitios del área Chuquicamata-Tomic.

En efecto, a unos 10-15 km al noroeste del río Loa (estación Conchi), mayormente en las quebradas llamadas de la Aguada, en razón de la principal vertiente ubicada en su cabecera y quebrada
Las Ruinas, se localizaron sitios vinculados con minas prehispánicas, incluyendo el sector colonial de la fundición de Conchi Viejo, en cotas altas del orden de los 3.000 a 3.500 m.snm. Preci- 
samente, en la segunda quebrada se ubicaron sitios relacionados directamente con la principal mina inca local llamada El Abra (Ab-35, Ab-36, Ab-37 y Ab-38) (Núñez 1999; Salazar et al. 2001).

En El Abra, la presencia de socavones amplios, canchas, muros de contención de aluviones sobre el área de extracción, junto a cientos de martillos, campamentos de fuerza de tareas y un gran asentamiento inca, dan cuenta de una activa labor en torno a las vetas cupríferas locales. El inicio de la ocupación del sitio ha sido datado por $\mathrm{C}^{14}$ (carbón) en una edad calibrada de 1475 a 1675 DC (Núñez 1999). Este rango de tiempo se relaciona, en su sigma mínimo, con los asentamientos incas locales, de momentos posteriores a la Fase Quinchamale del Loa Superior, es decir, hacia 1470-1535 DC (Berenguer 1995).

En relación a la cronología posterior al inca se han identificado vestigios de fundición junto a la iglesia de Conchi Viejo, donde se ha documentado la localización de un importante centro minero perteneciente al siglo XVIII, que incluía la mano de obra local atacameña. En este sentido, las vetas de las quebradas de Las Aguas y Las Ruinas no parecen haberse explotado intensamente después del episodio inca-local, sin reocupaciones coloniales hispánicas (Núñez 1999).

Hasta ahora, no se habían registrado ocupaciones extractivas prehispánicas fuera del Loa, constituyendo los sitios del sistema Chuquicamata-Tomic y El Abra los primeros en afiliarse por su cerámica, martillos y estructuras residenciales y de labor, a una etapa inca-local y anterior (Núñez 1999; Salazar et al. 2001). Aunque los sitios del sistema inca son más o menos sincrónicos, se propone una secuencia tentativa en donde las primeras labores extractivas habrían ocurrido en los campamentos Ab-37 y Ab-38, más cercanos a la mina nativa, aproximadamente en un rango entre 1105-1305 DC, a 1285-1495 DC (últimos eventos en Ab-38). El clímax productivo y demográfico habría ocurrido posteriormente, durante la ocupación del poblado principal Ab-36, asociado a indicadores culturales homólogos a los sitios anteriores, datados entre 1475-1675 DC. Dada la ausencia de restos europeos, este sitio estuvo en uso entre 1300 a 1475 DC. La cerrada correlación entre las fechas $\mathrm{C}^{14}$ recibidas y los contextos sincrónicos inca-población local, vienen a ratificar la colonización minera de El Abra entre 1300-1475 DC, como resultado de una efi- ciente política de incremento de la producción minera administrada por el régimen incaico (Núñez 1999).

\section{El campamento minero-extractivo Chu-2}

El sitio Chu-2 se ubica a unos $1.500 \mathrm{~m}$ al noroeste del actual yacimiento Chuquicamata, a 3.050 $\mathrm{m} . \mathrm{snm}$, adyacente a rutas caravaneras que pasan a los pies de la ladera en que se emplaza. Como ya se ha señalado, corresponde a un campamento minero preincaico compuesto por ocho recintos semicirculares, emplazados hacia la pendiente, a modo de paravientos, con depósitos de desperdicios estratificados (Figuras 2 y 3 ).

Los principales atributos constructivos indican el uso de grandes paravientos de bloques de granito no modificados, los que fueron depositados directamente sobre la superficie, ya que no se aprecian fundamentos, salvo en algunas estructuras (Tabla 2). Aunque en la mayor parte de los recintos no es discernible, el tipo de hilada es simple, desaplomada, con parte importante de los muros abatidos, tanto hacia el exterior como al interior de las estructuras. En el recinto 4 -el mejor conservado del sitio-, fue posible observar dos sistemas de construcción: formando cuñas, es decir, apilamiento de piedras de tamaño mediano por el exterior que sostienen un bloque interior de mayores dimensiones, y el apilamiento de piedras medianas que no alcanzan a formar hiladas, siendo estos últimos los que mejor se conservan. La factura de los recintos manifiesta una construcción y uso expeditivo, sugiriendo, por una parte, escasa inversión de trabajo en su elaboración y mantención, y, por otra, ocupaciones poco prolongadas.

Los recintos suelen estar abiertos hacia el este, con la salvedad del recinto 8, expuesto al sur. Los recintos 3 y 4 presentan ligeros taludes en su apertura, indicando cierta delimitación del espacio ocupado. A su vez, el recinto $5 \mathrm{~A}$ es el único que se halla completamente cerrado, encontrándose, además, adosado a $5 \mathrm{~B}$, y presenta una pequeña estructura complementaria de forma subcircular de unos $65 \mathrm{~cm}$ de diámetro. Es también, el único recinto en que se observaron concreciones de piedras, sílices y sedimentos, que pudieron usarse como mortero.

La mayor parte de estas estructuras presentan escaso material de superficie, tanto al interior como 


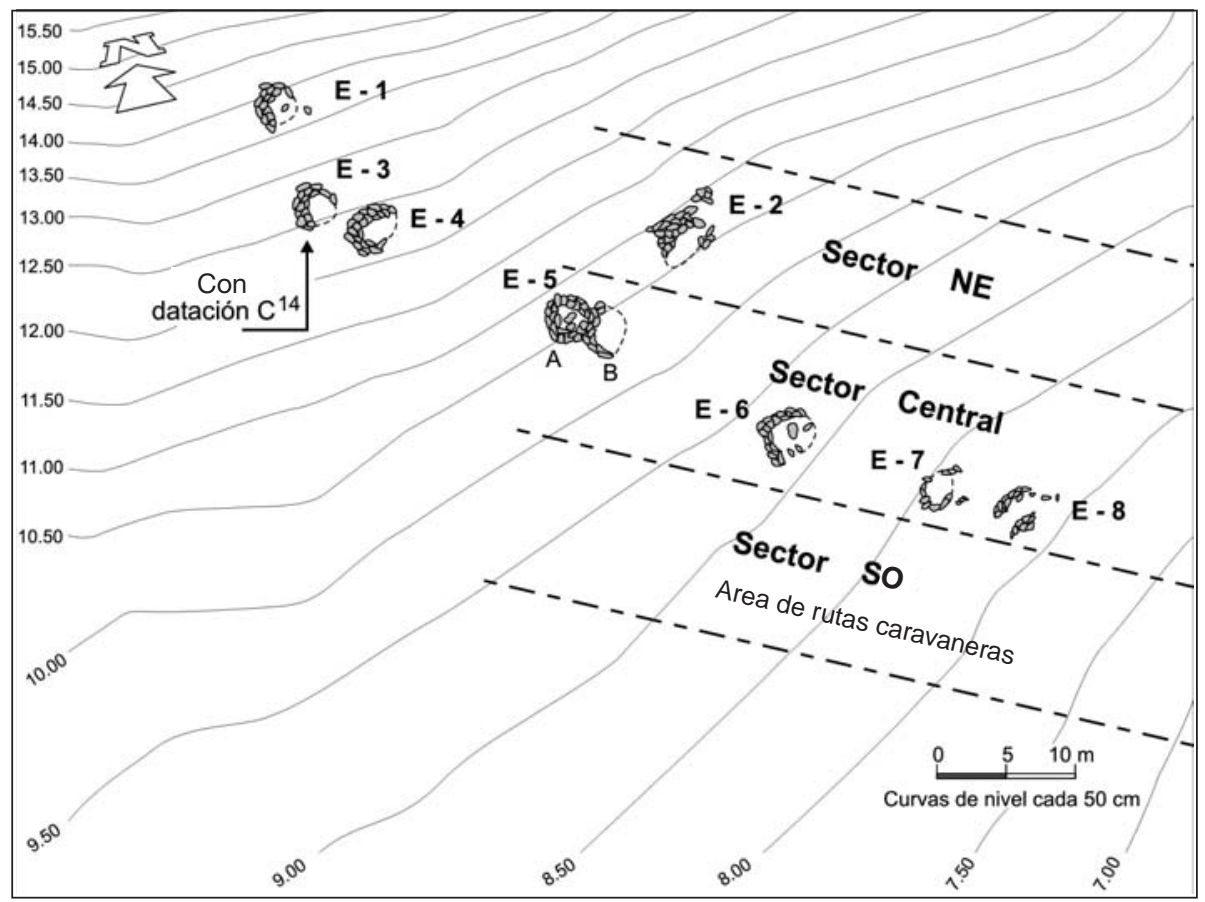

Figura 2. Plano topográfico con la ubicación de los recintos y sectores estudiados en Chu-2.

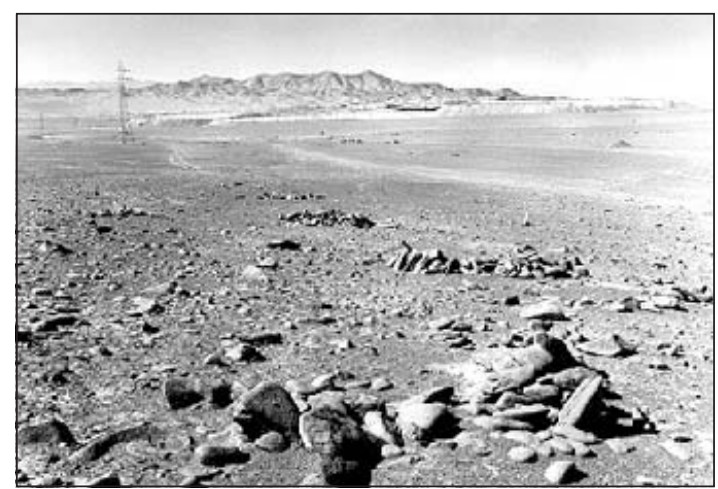

Figura 3. Panorámica del sitio Chu-2. Al fondo se observa la actual mina de Chuquicamata.

al exterior, o sencillamente no lo presentan. Este es el caso de los recintos 1,3 y 8 , mientras que en los restantes la densidad de hallazgos superficiales es baja, con la salvedad del recinto 4 que aparece como el más denso del sitio, con una distribución de los hallazgos hacia los muros y bordes, los que consisten en materiales subactuales. Dentro de esta relativa escasez de material superficial, se recuperaron fragmentos cerámicos, mineral de cobre, semillas de algarrobo, ramas, huesos, papel, cenizas y carbón.
Además del material superficial inmediatamente adyacente a los muros internos y externos, se detectó una zona de unos $5 \mathrm{~m}$ entre los recintos 5 y 6 , que concentraba mayor cantidad de cerámica y líticos, los que fueron recolectados a través de una sectorización NE, Central y NO (Figura 2).

El sector suroeste tuvo la mayor concentración de materiales, especialmente en lo que se refiere a fragmentos de cerámica, además de restos de mineral de cobre, desechos líticos y, en menor medida, restos malacológicos e instrumentos líticos. Dentro de estos últimos, destaca la base de una punta de proyectil de base escotada, confeccionada en cuarzo (sector noreste) y otros artefactos reducidos de cuarzo y calcedonia local. A juzgar por la identificación de fragmentos de conchas del Pacífico y erizos (Loxechinus albus), quienes utilizaron este sitio se habrían desplazado tras recursos mineros y de subsistencia en una amplia escala geográfica. También utilizaron rocas locales como granito, andesita y basalto para la confección de martillos y palas similares a las agrícolas, pero esta vez aplicadas en las labores mineras (Bird 1977 y 1979; Uribe y Carrasco 2000). La presencia de atacamita y crisocola se correlaciona con la extracción de afloramientos ubicados en la serranía cercana al suroeste del sitio, de 
LAUTARO NUÑEZ A., CAROLINA AGÜERO P., BARBARA CASES C., PATRICIO DE SOUZA H.

\begin{tabular}{|c|c|c|c|c|c|c|c|}
\hline$\infty$ & 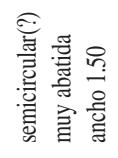 & 器 & 受 & 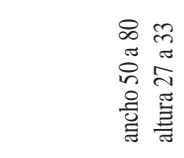 & 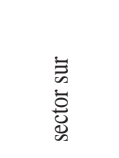 & $\sigma$. & 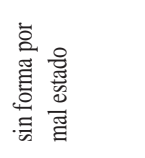 \\
\hline 되 & 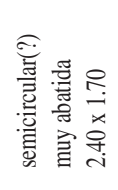 & 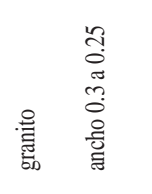 & 爰 & 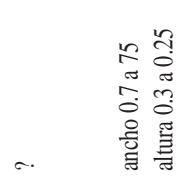 & 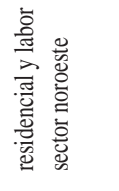 & - & 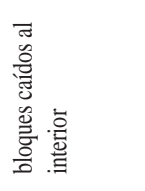 \\
\hline 도 & 营 & 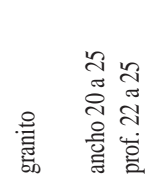 & 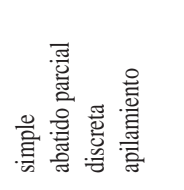 & 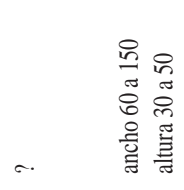 & 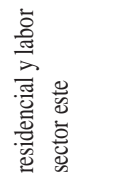 & $a$. & 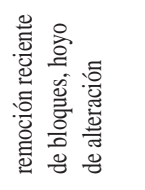 \\
\hline $\begin{array}{l}\text { कि } \\
\text { เિ }\end{array}$ & 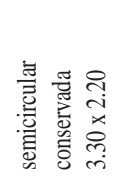 & 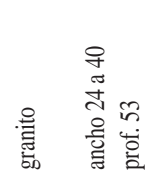 & 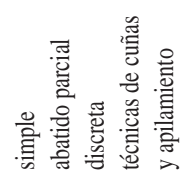 & 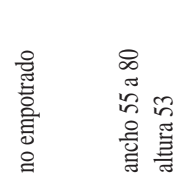 & 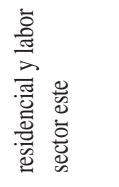 & 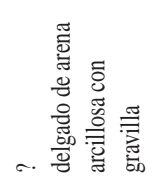 & 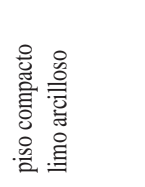 \\
\hline 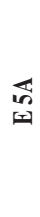 & 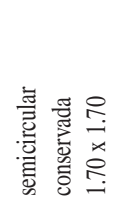 & 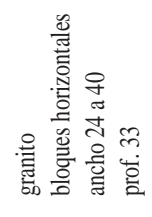 & 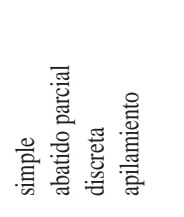 & 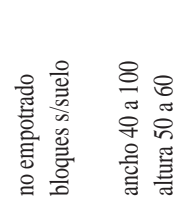 & 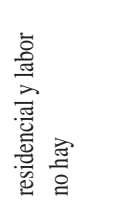 & 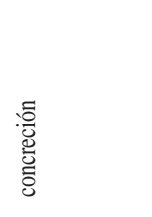 & 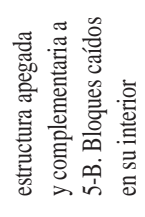 \\
\hline 坣 & 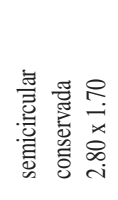 & 黄 & 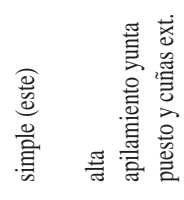 & 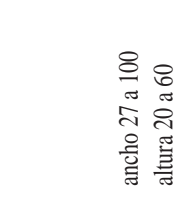 & 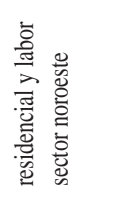 & $a$. & 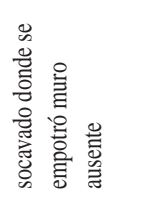 \\
\hline 9 & 袅 & 器 & 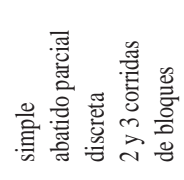 & 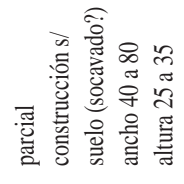 & 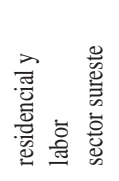 & $a$. & 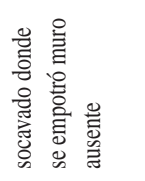 \\
\hline 조 & 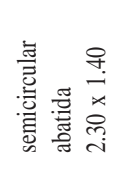 & 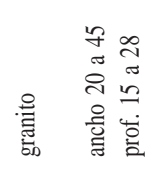 & 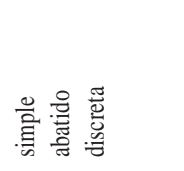 & 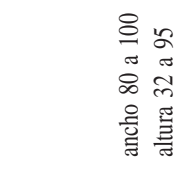 & 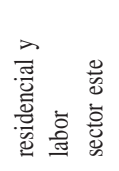 & 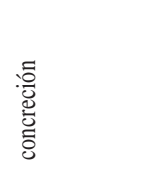 & \\
\hline$\vec{x}$ & 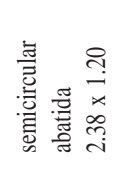 & 檗 & 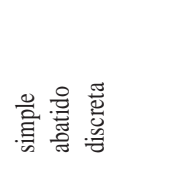 & 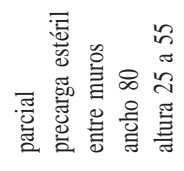 & 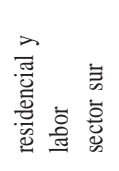 & $\sigma$. & \\
\hline 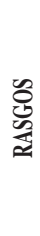 & 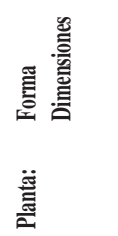 & 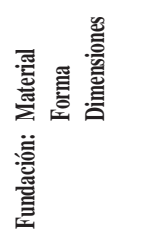 & 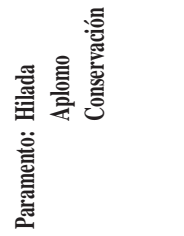 & 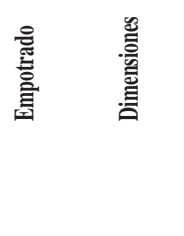 & 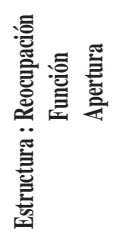 & 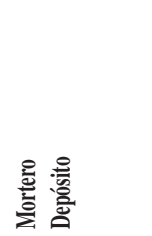 & 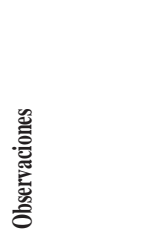 \\
\hline
\end{tabular}


tal modo que las labores de extracción no debieron ocurrir más allá de los 500 a 3.000 m de distancia del campamento.

Dentro de la escasez de material cultural de superficie, la cerámica permite afirmar algunos aspectos preliminares sobre la ocupación del sitio (Tabla 3). Hacia el suroeste de las estructuras de Chu-2 domina el componente cerámico tarapaqueño del Período Intermedio Tardío a través de la alfarería tarapaqueña Pica/Charcollo, introducida por rutas que unen Quillagua y el Loa Medio. No obstante, se registró un segundo componente cerámico, esta vez de San Pedro de Atacama, representado por alfarería Sequitor, del final del Formativo y Período Medio el cual además está apoyado cronológicamente por cerámica Loa Rojo Alisado y por aquella característica de las fases Quitor y Coyo, todas anteriores a los 900 DC. De este modo, se observó tentativamente una ocupación del sector por poblaciones del Loa y San Pedro de Atacama que podrían ubicarse entre los 400-900 DC, para posteriormente haber logrado una estrecha relación con grupos caravaneros de Tarapacá. Esto habría ocurrido a partir del 900 DC hasta por lo menos 1300 DC, siendo concordante con la situación detectada en el valle de Quillagua, donde se pensaba que la penetración tarapaqueña alcanzaba hasta este límite (Agüero et al. 1997 y 1999).

Hacia el noreste de las estructuras, la composición alfarera cambia, mostrando el sitio una ocupación formativa consistente y representativa del Loa, a través de los tipos Loa Café Alisado (LCA),
Quillagua Café Amarillento (QTC), Sequitor y Loa Rojo Alisado, para posteriormente evidenciar un momento Intermedio Tardío coherente con su ocupación anterior, ya que está representado por un componente netamente loíno, como lo es la cerámica Aiquina (AIQ).

En el sector transicional entre los recintos estructurados y las rutas, se recuperaron en recolecciones previas al Proyecto (Núñez 1999 Ms), 147 fragmentos correspondientes principalmente a cerámica Aiquina y Hedionda (Figura 4) del Período Intermedio Tardío, habiendo también alfarería de períodos anteriores como la Fase Sequitor (tiestos gris a negro pulido), lo que confirma el inicio de la ocupación durante los últimos eventos formativos.

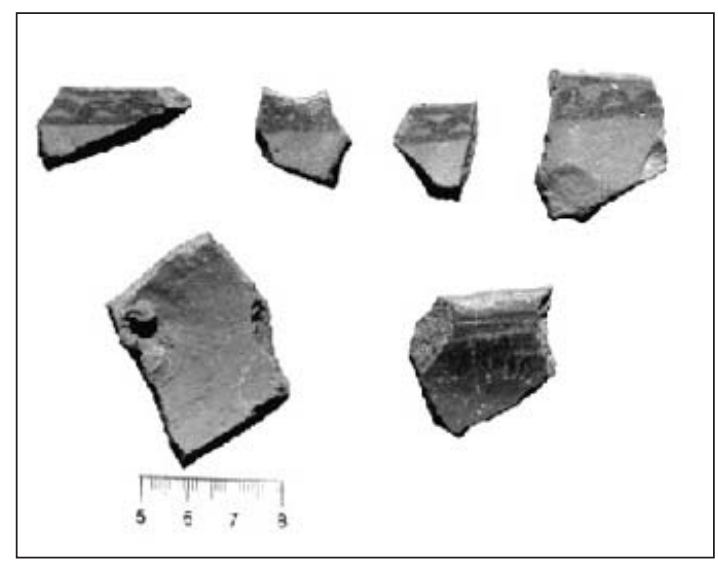

Figura 4. Cerámica Hedionda registrada en los recintos y rutas asociadas a Chu-2.

\begin{tabular}{|c|c|c|c|c|c|c|c|c|c|}
\hline \multirow[t]{2}{*}{ Tipos cerámicos } & \multicolumn{2}{|c|}{ Recinto 2} & \multicolumn{2}{|c|}{ Recinto 5B } & \multirow{2}{*}{$\begin{array}{c}\text { Sector } \\
\text { SO }\end{array}$} & \multirow{2}{*}{$\begin{array}{l}\text { Sector } \\
\text { NE }\end{array}$} & \multirow{2}{*}{$\begin{array}{l}\text { Sector } \\
\text { Central }\end{array}$} & \multirow[t]{2}{*}{ TOTAL } & \multirow[t]{2}{*}{ Porcentaje } \\
\hline & Ext. & Int. & Ext. & Int. & & & & & \\
\hline Pica-Charcollo (PCH) & & & & & 25 & & & 25 & 26.04 \\
\hline Aiquina (AIQ) & 3 & & & & & 11 & & 14 & 14.58 \\
\hline Turi Rojo Alisado (TRA) & & & 2 & & & & & 2 & 2.08 \\
\hline Hedionda (HED) & & & 1 & 1 & & & & 2 & 2.08 \\
\hline Loa Rojo Alisado (LRA) & & & & & 1 & 1 & & 2 & 2.08 \\
\hline (Corresp. a fases Quitor-Coyo) & & & & & 3 & & & 3 & 3.13 \\
\hline Cerámica "Coyo" & & & & & 1 & & & 1 & 1.04 \\
\hline Sequitor & & & 1 & & 10 & 2 & & 13 & 13.54 \\
\hline Loa Café Alisado (LCA) & & & 1 & & & 1 & 12 & 14 & 14.58 \\
\hline Quillagua Café Amarillento (QTC) & 2 & & & & & 4 & & 6 & 6.25 \\
\hline NR/Erosionados (ERO) & 1 & 1 & 1 & & & 10 & 1 & 14 & 14.58 \\
\hline TOTAL & 6 & 1 & 6 & 1 & 40 & 29 & 13 & 96 & 100 \\
\hline Porcentaje & 6.25 & 1.04 & 6.25 & 1.04 & 41.67 & 30.21 & 13.54 & 100 & \\
\hline
\end{tabular}

Tabla 3. Material cerámico en superficie. 
Finalmente, al comparar estos materiales entre los campamentos y rutas del área de estudio, se desprende que la cerámica más popular es aquella del Período Intermedio Tardío (900-1450 DC), integrada por los componentes Loa-San Pedro (Aiquina) y Altiplánico (Hedionda), el cual al presentarse en las rutas de Chu-9, plantea una contemporaneidad de ambos eventos. Por su parte, el tipo Aiquina establece relaciones sincrónicas entre los sitios Chu-2, Chu-5 y Chu-9, como los alisados a pulidos tardíos establecen vínculos entre Chu-5 y Chu-2 (Tabla 1). Algo similar ocurre con el tipo Turi Rojo Alisado en Chu-5, Chu-2 y Chu-7. A juzgar por la cerámica de la Fase Coyo (Figura 5), todo parece indicar que las rutas de Chu-2 y sus estructuras presentan alfarería común, dando cuenta de los inicios de ocupación antes de lo admitido. La presencia de escasos fragmentos del tipo Yavi ejemplifican la pervivencia del tráfico asociado a estos campamentos mineros hasta de expansión inca (Chu-2 y Chu-1). Por otra parte, el registro de botijas españolas en los sitios Chu-5 y Chu-7, indican que los campamentos y paskanas continuaban en uso durante la expansión del régimen español.

Entre el material lítico son frecuentes las palas en Chu-5, además de las puntas pedunculadas, desechos de percusión de calcedonia del Loa y martillos pesados. La presencia de hojas y mazorcas de maíz, conchas del Pacífico y mineral de cobre, junto al machacado de atacamita tanto en Chu-5 como Chu-2, da cuenta de la alta complejidad en términos de traslados de bienes de larga distribución.

Los contextos cerámicos con distintos componentes, asociados a rutas y campamentos de extracción y molienda de atacamita, es coherente con el tráfico de larga distancia que conecta espacios

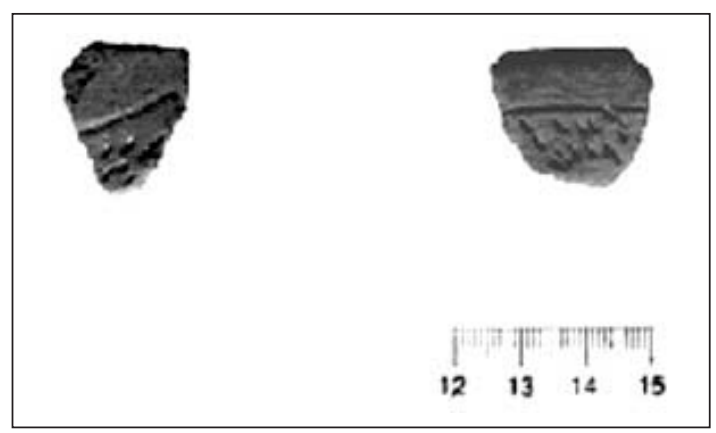

Figura 5. Cerámica incisa "Coyo", representativa de los oasis de San Pedro de Atacama a fines del Período Medio. altiplánicos y costeros, a través del paso y permanencia por cortas temporadas junto a las vetas expuestas en la serranía de Tomic-Chuquicamata. Precisamente, esta idea se intentará contrastar con los tests cronoestratigráficos aplicados en Chu-2.

Que este campamento se sitúe en un territorio con vetas expuestas, pero inhóspito, sin recursos de subsistencia, demuestra su finalidad minera desde las postrimerías del Período Formativo hasta el Intermedio Tardío, constituyendo el primer asentamiento de este tipo reconocido en el sector de Chuquicamata-Tomic. Se ha indicado que entre las estructuras y rutas se observaron distintos componentes cerámicos de tradiciones preincaicas de las cuencas del Loa y de Atacama, así como de la región de Tarapacá. Este hecho así como la relación entre extracción de cobre y rutas sitúan a Chu-2 entre uno de los sitios claves para entender las labores mineras fuera de los valles y, por lo tanto, es importante conocer debidamente sus contextos cronoestratigráficos.

\section{Las pruebas cronoestratigráficas}

De acuerdo a los resultados de la recolección superficial, las excavaciones se realizaron en las estructuras que, de acuerdo al registro de depósito, mostraban la mayor concentración de materiales culturales en su interior y/o exterior (Recintos 2, 3, 4, 5A, 5B, 6). Se buscó cubrir muestrealmente los bordes y espacios interiores del sitio, para comprender su funcionalidad. Asimismo, se realizó un pozo externo de $1 \mathrm{~m}^{2}$, situado en un sector representativo de las actividades fuera de las estructuras (ver Figura 2).

\section{Recinto 2}

Corresponde a una estructura semicircular de aproximadamente $3 \mathrm{~m}$ por $1.5 \mathrm{~m}$. La hilada de los muros es simple, desaplomada, con una altura promedio de $40 \mathrm{~cm}$ y un ancho promedio de $1 \mathrm{~m}$. Especialmente hacia el muro oeste, se encuentran numerosas piedras abatidas hacia el exterior. El área interior parece haber sido inicialmente despejada, si bien actualmente presenta piedras derivadas del colapso de los muros. En la superficie interna, y especialmente en el sector de los muros y bordes, se observó una pequeña cantidad de fragmentería cerámica, partículas de mineral de cobre y semillas de algarrobo. En la superficie adyacente exterior se encontraron escasos fragmentos de cerámica y semillas de algarrobo. 


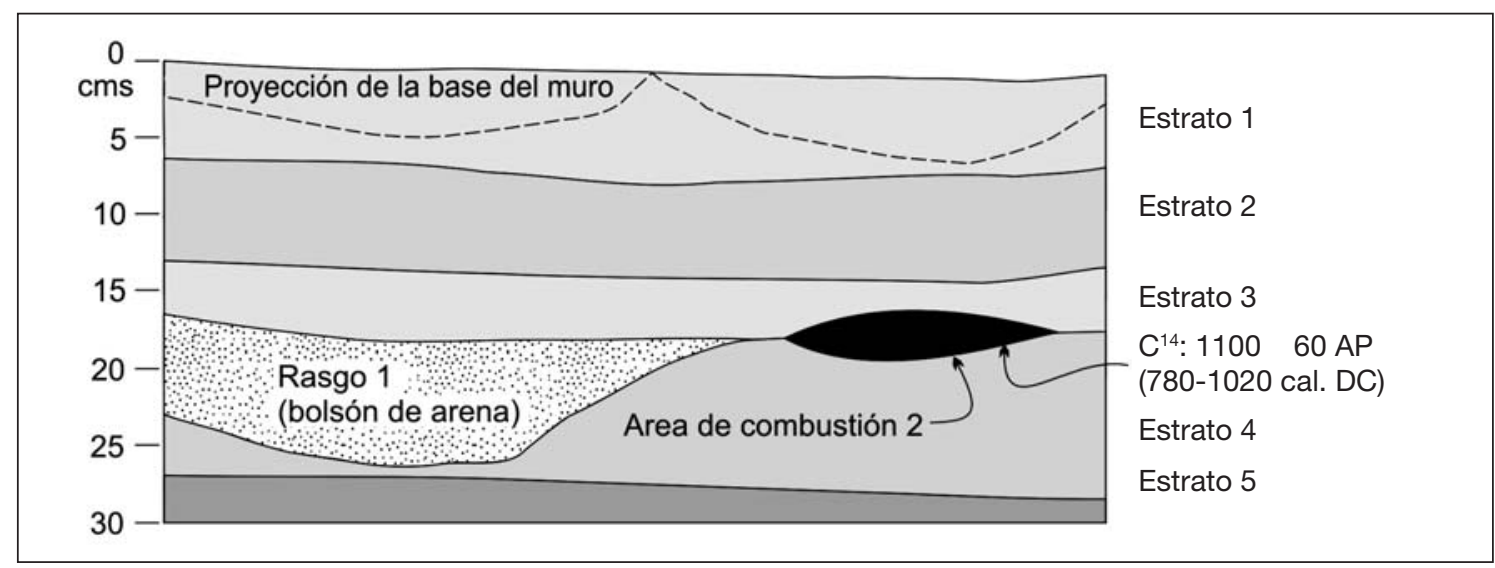

Figura 6. Perfil estratigráfico NO de la unidad B2 del Recinto 3, con indicación de la ubicación de la muestra datada por $\mathrm{C}^{14}$.

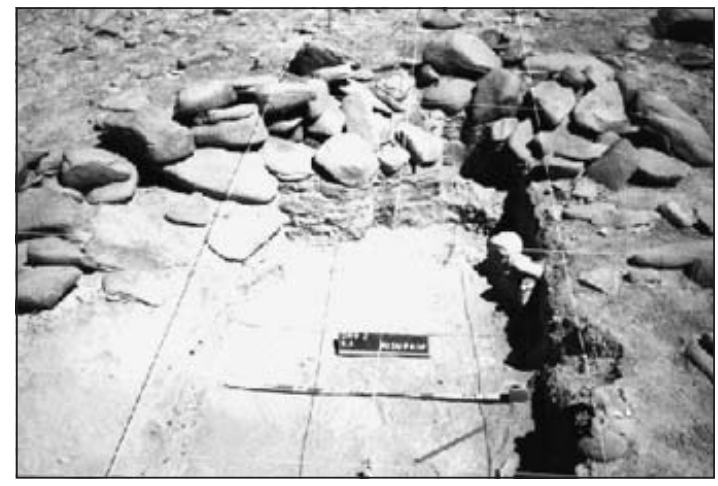

Figura 7. Detalle de la excavación del Recinto 3.

El recinto fue dividido espacialmente en 8 unidades de 1 x $0.75 \mathrm{~m}$. Los sectores correspondientes a las unidades B4 y C4 no fueron excavados, conservándose como testigos. Se excavó un total de 6 unidades (B1, B2, B3, C1, C2, C3), con un máximo de $20 \mathrm{~cm}$ de profundidad en la unidad $\mathrm{B} 2$, siendo $15 \mathrm{~cm}$ el promedio en el resto de las unidades. En ella se identificaron 3 depósitos sucesivos.

El estrato 1 corresponde a un sustrato arenoso mezclado con abundante gravilla y algunos clastos angulosos, de consistencia disgregada y color café grisáceo. Tiene una profundidad de entre 9 y 5 $\mathrm{cm}$, siendo el último valor su espesor promedio. Presenta la mayor concentración de material cultural dentro de esta estructura, que consiste principalmente a fragmentos de mineral de cobre y, en menor medida, coprolitos de camélido, escasos fragmentos cerámicos, astillas de hueso, vértebras de pescado, un fragmento de percutor $y$ restos vegetales.
El estrato 2 tiene una alta proporción de sedimentos limo-arcillosos, mezclados con arena y gravilla angulosa, de consistencia muy compacta y estructura aterronada, de color café amarillento. $\mathrm{Su}$ profundidad máxima alcanza los $9 \mathrm{~cm}$ en la unidad B1, siendo más frecuente un espesor de 3 a 6 $\mathrm{cm}$. En gran parte de la unidad C1 y parte de la $\mathrm{C} 2$, esta capa contiene un bolsón de arena (Rasgo 1), caracterizado por tener numerosos restos de carbón y escasos vegetales como ramas, semillas de algarrobo y cutículas no identificadas, correspondientes a un área de combustión muy difusamente definida. Presenta muy poco material cultural consistente en mineral de cobre, hojas de maíz y semillas de algarrobo.

El estrato 3, culturalmente estéril, está compuesto por un conglomerado salino extremadamente compacto, color blanco-grisáceo.

Llama la atención la alta frecuencia de carbones vegetales, sugiriendo funciones relacionadas con actividades de cocina (fogones), acorde a funciones más habitacionales (Gráfico 1).

\section{Recinto 3}

Se trata de una estructura semicircular abierta hacia el este (Figuras 6 y 7), de aproximadamente $2.4 \mathrm{~m}$ de largo máximo y $1.9 \mathrm{~m}$ de ancho máximo. La hilada de los muros es simple, desaplomada, con una altura promedio de $40 \mathrm{~cm}$ y un ancho de $75 \mathrm{~cm}$. Especialmente hacia el muro oeste, se encontraron varios bloques abatidos hacia el exterior. Ni el interior ni el exterior presentaron materiales culturales en superficie. El depó- 


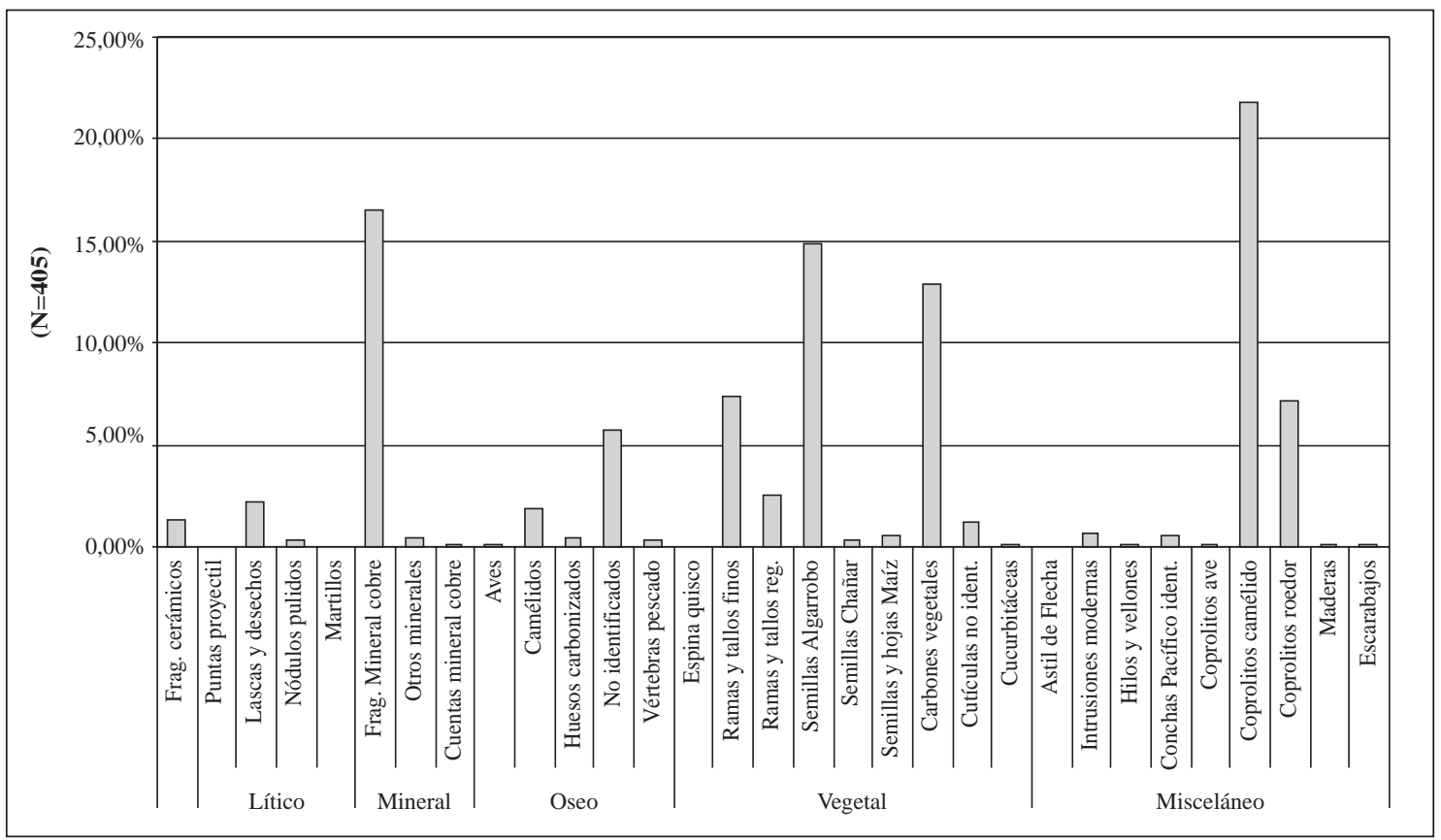

Gráfico 1. Recinto 2: Frecuencias porcentuales de categorías culturales.

sito interior estaba sensiblemente elevado sobre el nivel de superficie del depósito exterior, formando en el lado abierto de la estructura un pequeño "talud" que separa la superficie externa e interna del recinto, y que sigue un perímetro, aparentemente en continuidad con los muros actualmente presentes. Esto significa que la superficie interior del recinto fue socavada, amontonándose lo extraído en su contorno para elevar los bordes del espacio ocupado.

El recinto fue dividido en 12 unidades, de 1 x $0.60 \mathrm{~m}$, de las cuales se excavaron cinco: A2, A3, B2, B3, C3; esta última de forma irregular, por hallarse adyacente a los muros. El resto de las unidades fueron dejadas como testigos. Se excavó hasta un máximo de $30 \mathrm{~cm}$ de profundidad. En este recinto se identificó la estratigrafía más compleja del sitio, consistente en cinco depósitos sucesivos.

El estrato 1, correspondiente a un sustrato arenoso mezclado con gravilla y clastos angulosos, es de consistencia suelta y de color café grisáceo. $\mathrm{Su}$ profundidad fluctúa entre $\operatorname{los} 9$ y $5 \mathrm{~cm}$. Presenta una alta proporción de materiales culturales, principalmente mineral de cobre, semillas de algarrobo y coprolitos de camélido, y con menor frecuencia astillas de hueso, fragmentos cerá- micos, desechos de talla y una vértebra de pescado.

El estrato 2 presenta una alta proporción de sedimentos limo-arcillosos, mezclados con arena y gravilla angulosa; es de consistencia muy compacta y estructura laminar, con lentes muy delgados de arena intercalados. Es de color café amarillento con una profundidad entre $5 \mathrm{~cm}$ en la unidad B3, hasta $20 \mathrm{~cm}$ en C3. A partir de este estrato fue posible delimitar el perímetro de la unidad ocupacional del recinto, la que adquiere una curvatura en continuidad con los muros. Presenta poco material cultural como huesos astillados, mineral de cobre, retos vegetales, restos de maíz y coprolitos de camélido.

El estrato 3 consiste en un sustrato arenoso, mezclado con gravilla angulosa, de consistencia medianamente compacta y color café amarillento. Alcanza una profundidad máxima de $9 \mathrm{~cm}$ en las unidades A2 y A3, mientras que en B3 y B2 llega solo a $4 \mathrm{~cm}$. Cabe señalar que en la unidad C3, posiblemente producto de que se encuentra adosada al muro oeste, no se presenta el estrato 3 y el estrato 4 se funde con el estrato 2, lo que explica el gran espesor que adquiere este último. En este estrato nuevamente se registró bastante material cultural, principalmente orgánico (asti- 
llas de hueso, semillas de algarrobo y coprolitos de camélido), y en menor proporción, mineral de cobre y desechos líticos.

El estrato 4 es similar al 2, en cuanto se trata de un sustrato con alta proporción de sedimentos finos, mezclados con arena y gravilla angulosa, de consistencia muy compacta y estructura laminar, con lentes muy delgados de arena intercalados. Es de color café amarillento, con un máximo de $11 \mathrm{~cm}$ de profundidad en la unidad B3, y un mínimo de $3 \mathrm{~cm}$ en A2. En la unidad B3, en el techo se encontró un pequeño y difuso fogón, de unos $20 \mathrm{~cm}$ de diámetro y $1 \mathrm{~cm}$ de espesor, consignado como "Area de combustión 1", una pequeña parte del cual alcanzaba a la unidad B2. En ésta, en el techo de la capa se halló un fogón bien delimitado y con una alta concentración de carbón, de $15 \mathrm{~cm}$ de diámetro y $3 \mathrm{~cm}$ espesor, designado "Area de combustión 2". En la misma unidad, se detectó un bolsón de arena (Rasgo 1) que atraviesa desde el estrato 3 al estrato 4, tal vez correspondiente a un espacio dejado por una piedra que después fue extraída, que coherentemente presenta escaso material cultural. Esta situación es extensiva a la capa en su totalidad, en la que destaca el hallazgo de una cuenta de collar en la unidad B3.

El estrato 5 es culturalmente estéril y se compone de un sustrato arenoso mezclado con gravilla angulosa y una alta proporción de fragmentos de roca meteorizada; es de consistencia medianamente compacta y de color café grisáceo.

Se destaca la gran representación de semillas de algarrobo en relación a los otros recintos, como si se hubiera conservado allí el forraje llamero, acorde a la muy escasa presencia de artefactos líticos y fragmentos de cerámica (Gráfico 2).

\section{Recinto 4}

Es una estructura de aproximadamente $2.80 \mathrm{~m}$ por $1.70 \mathrm{~m}$. No se observan fundamentos y las piedras de granito que componen los muros no tienen intervención. Las dimensiones promedio de los paramentos son $70 \mathrm{~cm}$ de ancho y $45 \mathrm{~cm}$ de altura. El estado de conservación de todos los muros es regular, salvo el muro E que está alterado. El área interior del recinto estaba despejada. En relación a los paramentos, cabe destacar que existirían dos sistemas de construcción: a) en el muro norte, formando cuñas, es decir, apilamientos de piedras de tamaño mediano por el exterior que sostienen un bloque interior de mayores dimensiones, y b) en el muro oeste, apilamientos de piedras medianas que no alcanzan a formar hiladas. Estos últimos son los que mejor se conservan. Presenta un ligero talud que parece estar delimitando la estructura en su lado este.

Para excavar este recinto, se trazaron 12 cuadrículas de $1 \mathrm{~m}^{2}$, de las que se excavaron 7 (A2, A3, B2, $\mathrm{B} 3, \mathrm{C} 1, \mathrm{C} 2$ y C3) dejando al resto como testigos. Se excavó un máximo de $27 \mathrm{~cm}$ en la unidad B2 y un mínimo de $9 \mathrm{~cm}$ en $\mathrm{C} 1$.

El estrato 1 se compone de un sustrato arenoso mezclado con abundante gravilla y algunos clastos angulosos, de consistencia disgregada y color café grisáceo. Tiene una profundidad de entre 3 y 8 $\mathrm{cm}$. El material cultural consiste en un fragmento de concha, mineral de cobre, una astilla de hueso, una semilla de algarrobo, fragmentos de cerámica, coprolitos de camélido, un trozo de carbón, ramas y material subactual (proveniente de las unidades B2, C1 y C2). De este estrato proviene un astil decorado, uno de los pocos artefactos de madera encontrados en toda la excavación, situado entre las unidades $\mathrm{C} 1$ y $\mathrm{C} 2$.

El estrato 2 constituye un sustrato con alta proporción de sedimentos limo-arcillosos, mezclados con arena y gravilla angulosa, de consistencia medianamente compacta y estructura laminar, de color café claro anaranjado. Tiene un espesor de 3 a $18 \mathrm{~cm}$, correspondiendo su mayor profundidad a irregularidades y grietas del estrato 3 , en la cual se inserta, a modo de bolsones, situación claramente evidente en la unidad A2 (consignada como Bolsón). Contiene materiales culturales como carbón, ramas, un fragmento de hueso, mineral de cobre, semillas de algarrobo, un hueso astillado, maíz, una semilla de calabaza, coprolitos de camélido, parte de un escarabajo y material subactual. Al avanzar en profundidad disminuye notablemente la densidad del material recuperado. En la unidad B3, prácticamente en el techo del estrato, se individualizó el Rasgo 1, correspondiente a un fogón de $26 \mathrm{~cm}$ de diámetro, que alcanza una profundidad máxima de $24 \mathrm{~cm}$ y presenta una gran concentración de cenizas, carbón y restos orgánicos quemados de mayor tamaño. Es de sección subcónica, y para formarlo se cavaron los estratos 2 y 3 -este último correspondiente a la base del fogón-quedando los sectores ad- 


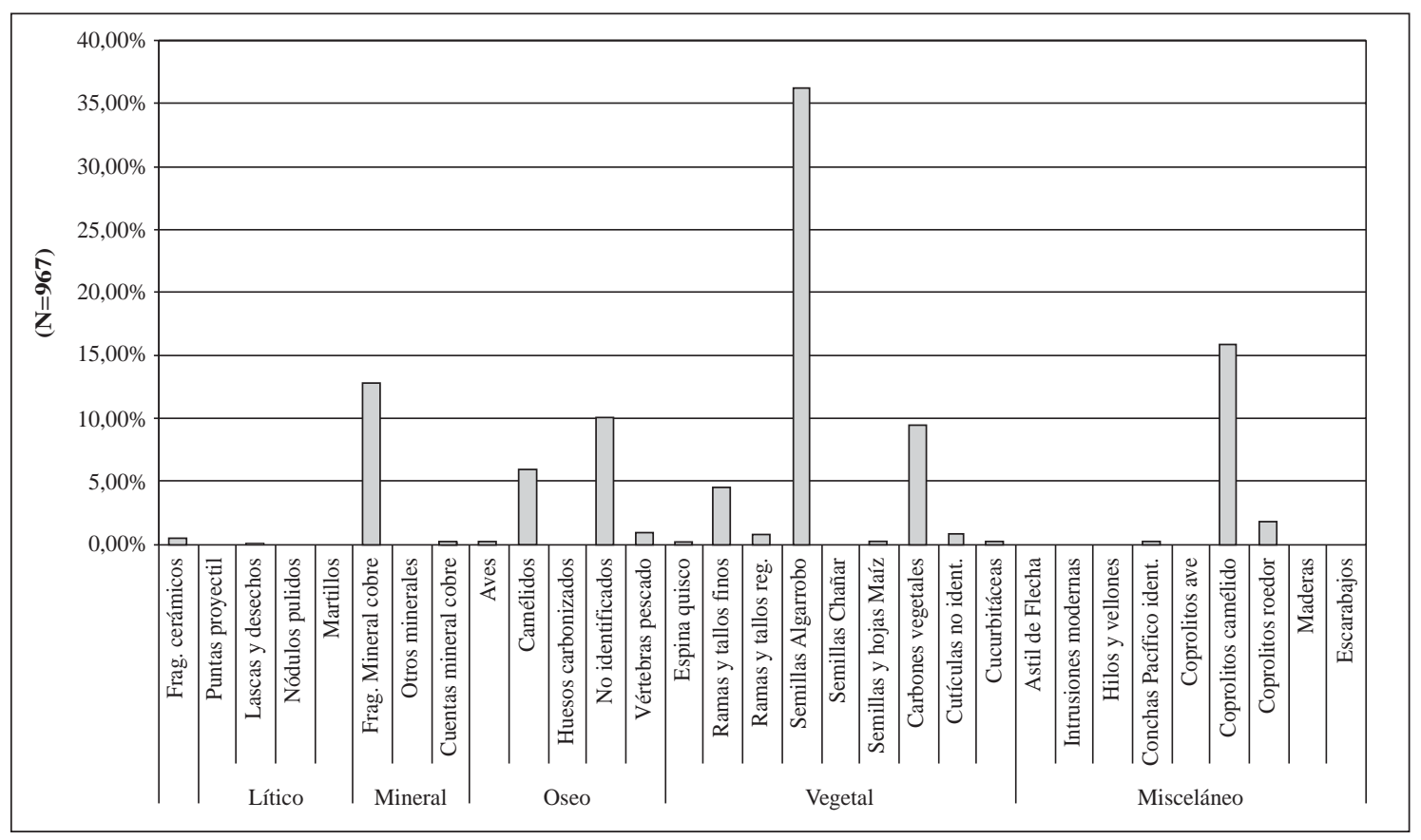

Gráfico 2. Recinto 3: Frecuencias porcentuales de categorías culturales.

yacentes sumamente compactos a raíz de la alta temperatura.

El estrato 3, culturalmente estéril, consiste en un sustrato arenoso mezclado con gravilla angulosa y una alta proporción de fragmentos de roca meteorizada; es de consistencia medianamente compacta, de color café grisáceo, y como se ha señalado presenta una superficie sumamente irregular, formando grietas y bolsones.

En contraste con la baja frecuencia de material lítico y cerámico, destaca la gran representación de coprolitos de camélidos, que guardaría relación con fogones intramuro asociados a una gran cantidad de mineral de cobre triturado, tal vez preparado al interior del recinto (Gráfico 3).

\section{Recinto 5A}

Es una estructura de aproximadamente $1.52 \mathrm{~m}$ por $1.76 \mathrm{~m}$. Tanto la hilada como el aplomo de los muros no son discernibles, producto del derrumbe, gran parte del cual se produjo hacia el exterior del recinto. El aparejo es rústico y el trabajo es natural, siendo granito el material de construcción, con bloques de tamaño grande y forma irregular, que se encuentran en buen estado. Los pa- ramentos tienen un ancho promedio de $60 \mathrm{~cm}$ y $55 \mathrm{~cm}$ de alto y su estado de conservación es regular. Presenta una estructura complementaria (5Aa) en la esquina suroeste, de forma subcircular, de unos $65 \mathrm{~cm}$ de diámetro.

Corresponde al único recinto completamente cerrado, con estructura complementaria y adosada a otra estructura (5B). Finalmente, entre las piedras hay concreciones con piedras, sílices y sedimentos, que podrían haber constituido el mortero. Este atributo está presente también en el Recinto 2. La superficie interna tiene un gran bloque ( $i$ abatido de los muros?) que sellaba prácticamente la totalidad de la superficie actual del recinto. Se observan abundantes ramas pequeñas y restos de cartón, lo que indica su reutilización superficial en momentos subactuales.

Fueron trazadas 6 unidades subrectangulares, cada una de ellas de distintas medidas, con el objeto de cubrir la totalidad de la superficie, dejando el perfil noreste como testigo.

El estrato 1 consiste en un sustrato arenoso mezclado con abundante gravilla angulosa fina a media y algunos clastos angulosos, de consistencia disgregada y color café grisáceo. Se extiende en- 


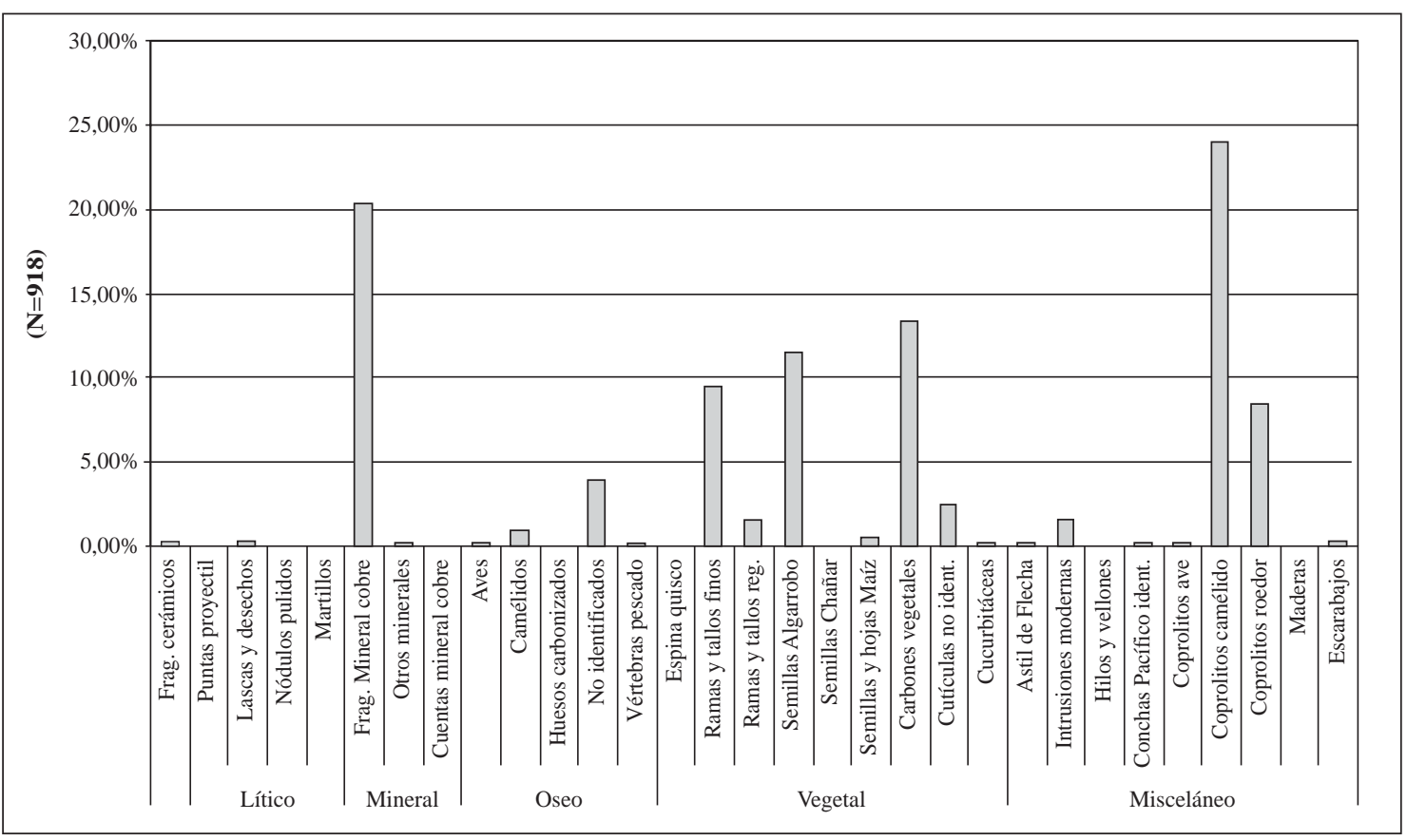

Gráfico 3. Recinto 4: Frecuencias porcentuales de categorías culturales.

tre 1 y $8 \mathrm{~cm}$, en las unidades $\mathrm{A} 3$ y $\mathrm{A} 1$, respectivamente. El material cultural corresponde a cerámica, mineral de cobre, material lítico, óseo, orgánico (maíz, ramas y cropolitos de camélido y material malacológico). En la unidad A1, se detectó el Rasgo 1 y 2, a $4 \mathrm{~cm}$ de profundidad, que se extiende por todo el estrato 2, hasta unos $18.5 \mathrm{~cm}$ de profundidad (en contacto con el estrato 3 ), consistente en restos de ceniza con material orgánico carbonizado, como coprolitos de camélido, ramas y roca meteorizada, bajo las cuales se halló una cuenta. Hacia el centro de la unidad B2, a unos 3 $\mathrm{cm}$ de profundidad, se observa un sector subcircular de material orgánico más potente, que se consignó como Rasgo 4; presentó una profundidad máxima de $15 \mathrm{~cm}$, atravesando el estrato 2. De su interior se recuperó madera, cenizas y carbón.

El estrato 2 se compone de un sustrato arenoso fino mezclado con gravilla fina y roca meteorizada, de consistencia medianamente compacta y color café claro. Se dispone irregularmente, es especial en los sectores este y norte de la unidad A1, y se inserta hacia la unidad A2 como un lente. Tiene una extensión entre 4 y $20 \mathrm{~cm}$. En la unidad A2, prácticamente en el techo de esta capa, a unos $3.5 \mathrm{~cm}$ de profundidad se detectó un pequeño lente de cenizas, consignado como Rasgo
2 , del cual se recuperaron escasos restos de ramas quemadas y varios coprolitos de camélido sin quemar, un fragmento de cerámica, líticos y mineral de cobre. En la unidad B1, a $8 \mathrm{~cm}$ de profundidad se detectó una pequeña área con cenizas consignada como Rasgo 3 de 12.5 de diámetro aproximado, y una profundidad máxima de $18 \mathrm{~cm}$, del que se recobran algunos coprolitos de camélido, carbón, un fragmento de concha y material orgánico. Hacia el oeste del recinto -en las unidades consignadas con letra B- el estrato 2 se inserta en las grietas y depresiones. Entre los materiales recuperados se cuentan mineral de cobre, fecas de roedor y camélido, una concha, carbón, un hueso astillado, semillas de algarrobo y un fragmento de calabaza.

El estrato 3, culturalmente estéril, se compone de arena y sedimentos limo-arcilloso finos, de consistencia muy compacta y color café claro anaranjado. Se sitúa a una profundidad entre 10 y $26.5 \mathrm{~cm}$.

Aunque hay una altísima frecuencia de coprolitos de camélidos, no es posible asegurar que esta estructura sea un corral. Dadas las bajas temperaturas nocturnas lo más probable es que los fogones cumplían varios propósitos con este combustible, 
dada la escasez de recursos leñosos en el área (Gráfico 4).

\section{Recinto 5B}

Es una estructura de forma semicircular, de aproximadamente $3.30 \mathrm{~m}$ por $2.10 \mathrm{~m}$, colindante con $5 \mathrm{~A}$ por el oeste. Los fundamentos observados en los muros sur y oeste tienen $30 \mathrm{~cm}$ de ancho promedio y $53 \mathrm{~cm}$ de profundidad. Al igual que los muros, se usaron bloques de granito de gran tamaño y sin cantear. No son discernibles hiladas ni aplomo en los muros. Los muros parecen haberse construido con el sistema de cuñas descrito para la estructura E4, siendo su ancho de $53 \mathrm{~cm}$ y la altura máxima de $80 \mathrm{~cm}$. Se observan escasas rocas que podrían haber caído de los muros.

Para la estructura se trazaron 10 cuadrículas de $1 \mathrm{~m}^{2}$, de las cuales se excavaron A2, A3, B1, B2, $\mathrm{B} 3, \mathrm{C} 1$ y $\mathrm{C} 2$, dejando el resto como testigo. La profundidad máxima del depósito fue de $19 \mathrm{~cm}$ en B2 y la mínima de $5 \mathrm{~cm}$ en A3.

El estrato 1, compuesto de un sustrato arenoso mezclado con gravilla angulosa y clastos angulosos, era de consistencia disgregada y color café grisáceo. Tiene un espesor mínimo de 3 a $5 \mathrm{~cm}$ y un máximo de $10 \mathrm{~cm}$ en la unidad $\mathrm{C} 1$. Es la capa más rica culturalmente, recuperándose de ella una astilla de concha, hilados, un vellón de camélido, biotita, mineral de cobre, semillas de algarrobo, ramitas, ramitas quemadas, coprolitos de camélidos, cerámica, líticos y lascas pequeñas de obsidianas alto andinas.

El estrato 3 se compone de un conglomerado salino extremadamente compacto, color blanco-grisáceo, sin material cultural dispuesto entre los 7 y $18 \mathrm{~cm}$ de profundidad.

La alta presencia de ramas y tallos da cuenta de la importancia en torno a la preparación de fogones antes referidos, trayéndose este material desde áreas más alejadas. Al igual que el Recinto 4, los fogones se asocian a una gran cantidad de coprolitos de camélido y mineral de cobre triturado, tal vez preparado al interior del recinto (Gráfico 5).

\section{Recinto 6}

Corresponde a una estructura de forma semicircular abierta hacia el este, de aproximadamente $3.7 \mathrm{~m}$ por $1.85 \mathrm{~m}$. La hilada de los muros es simple, desaplomada, con una altura y ancho prome-

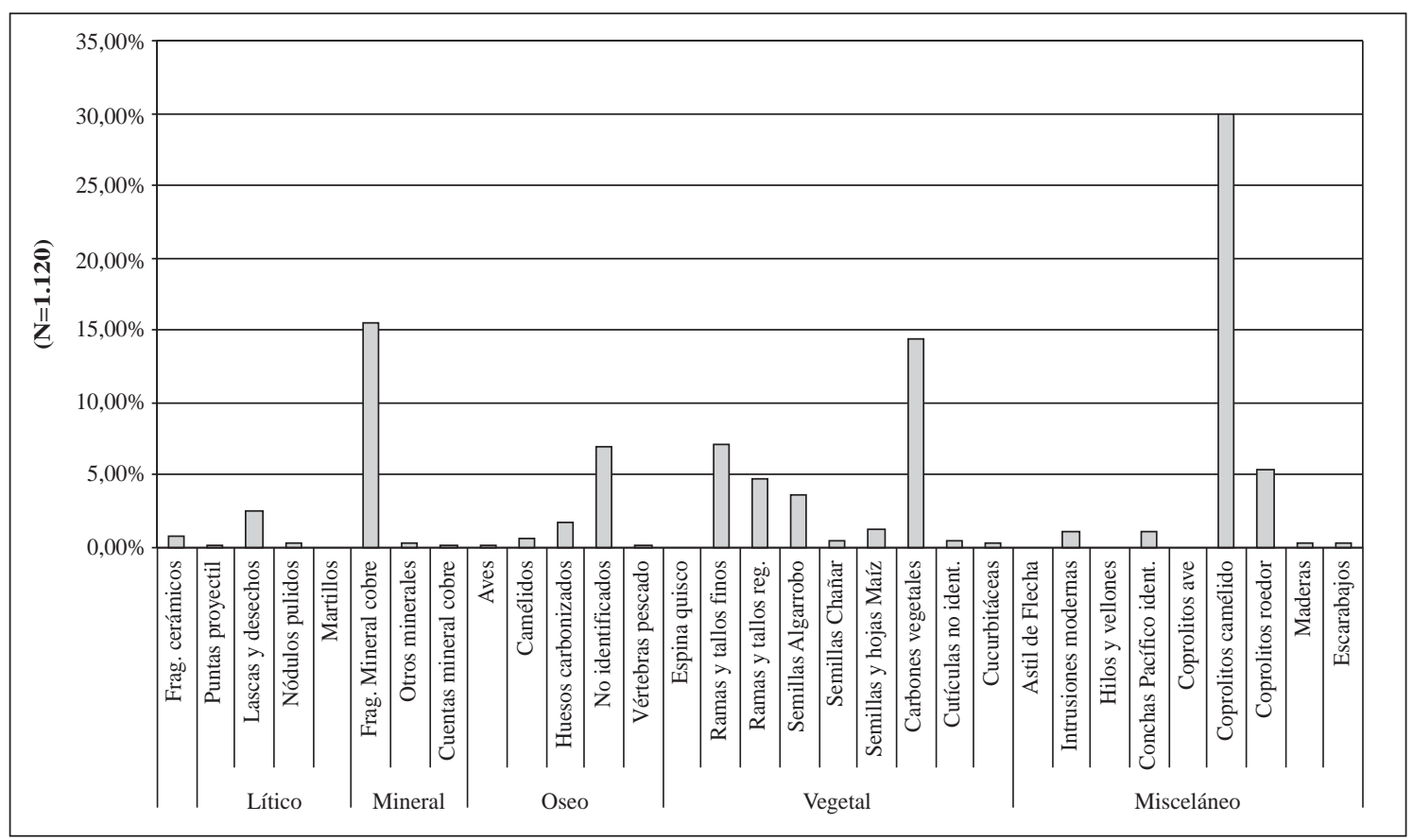

Gráfico 4. Recinto 5A: Frecuencias porcentuales de categorías culturales. 


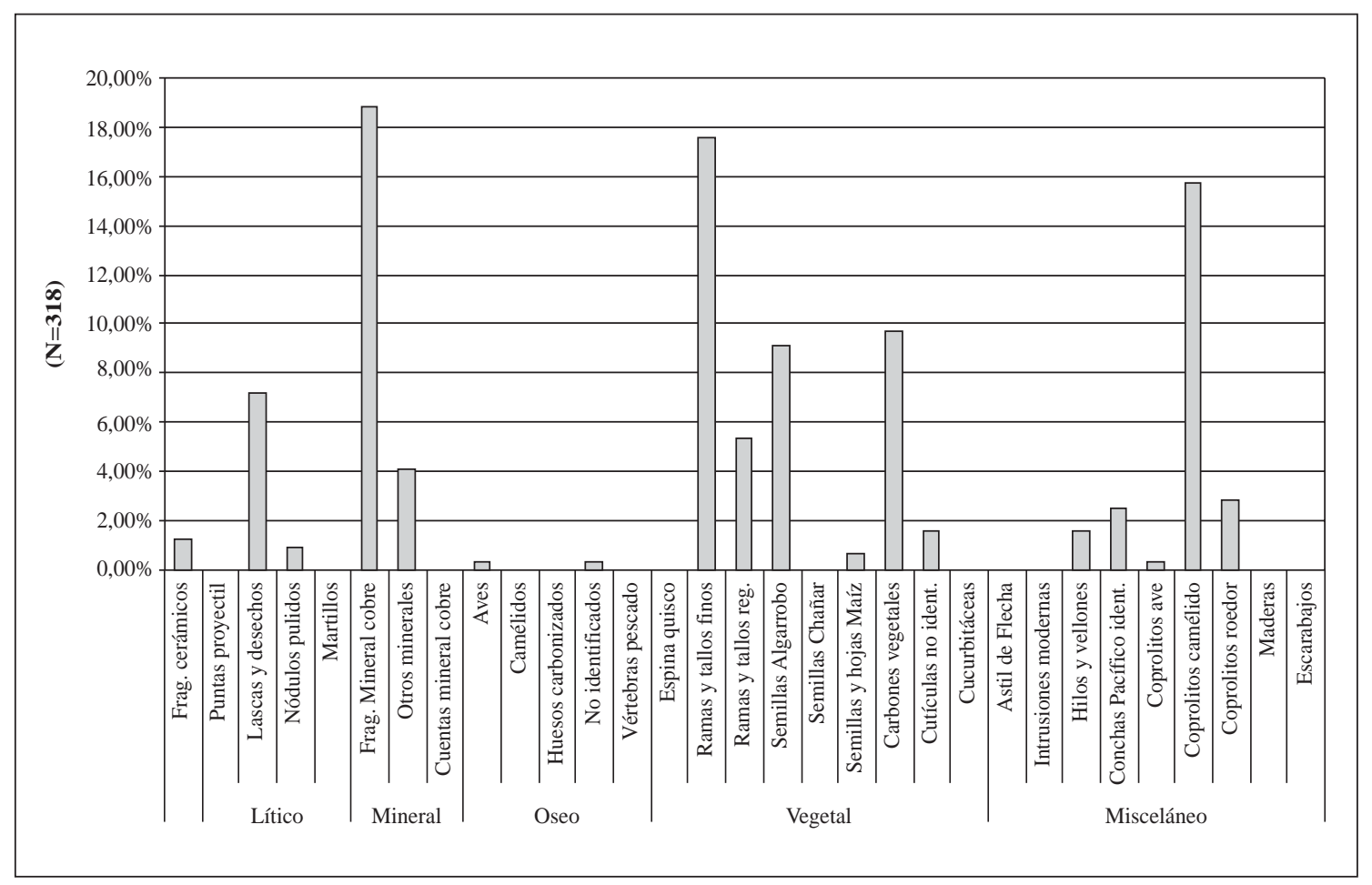

Gráfico 5. Recinto 5B: Frecuencias porcentuales de categorías culturales.

dio de $40 \mathrm{~cm}$ y $90 \mathrm{~cm}$, respectivamente. En especial en el muro oeste, se encuentran numerosas rocas abatidas hacia el exterior. El interior del recinto parece haber sido inicialmente despejado, aunque presenta rocas derivadas del colapso de los muros. Hay indicios de una remoción realizada con pala, que atravesó todo el depósito cultural en un área de $1 \mathrm{~m}$ por $0.7 \mathrm{~m}$, dejando dos montículos de tierra al interior del recinto. Otro hecho de interés es la presencia de al menos dos bloques con un desgaste muy localizado en una de sus superficies, tratándose aparentemente de pequeños morteros, posiblemente utilizados para moler cobre.

El recinto fue dividido en 12 unidades de $1 \mathrm{~m}$ por $0.8 \mathrm{~m}$, de las cuales se excavaron B2, B3, C1, C2, $\mathrm{C} 3$ y D2 por un máximo de $15 \mathrm{~cm}$ de profundidad, dejando al resto como testigo.

El estrato 1 está compuesto por un sustrato arenoso mezclado con gravilla y algunos clastos angulosos, de consistencia disgregada y color café grisáceo con un espesor de 2 y $6 \mathrm{~cm}$. El material cultural consiste principalmente en fragmentos de mineral de cobre y desechos líticos y, en menor medida, coprolitos de camélido, fragmentos cerámicos y astillas de hueso. En la unidad B2 destaca el hallazgo de una cantidad particularmente alta de mineral de cobre, lo que posiblemente se relacione con la cercanía de una de las plataformas usadas como yunques.

El estrato 2, de un espesor entre 7 y $11 \mathrm{~cm}$, se compone de un sustrato con alta proporción de sedimentos finos, mezclados con arena y gravilla angulosa, de consistencia muy compacta y estructura laminar, de color café amarillento. Presenta muy poco material cultural, el que se encuentra, principalmente dentro de los primeros $3-6 \mathrm{~cm}$.

El estrato 3 abarca entre los 12 y $14 \mathrm{~cm}$ de profundidad y es estéril. Está formado por un sustrato arenoso mezclado con gravilla angulosa y una alta proporción de fragmentos de roca meteorizada. Su consistencia es medianamente compacta, de color café grisáceo y culturalmente estéril.

Como en los Recintos 4, 5A y 5B destaca la gran cantidad de coprolitos de camélido, y en este caso también de roedor (Gráfico 6). 


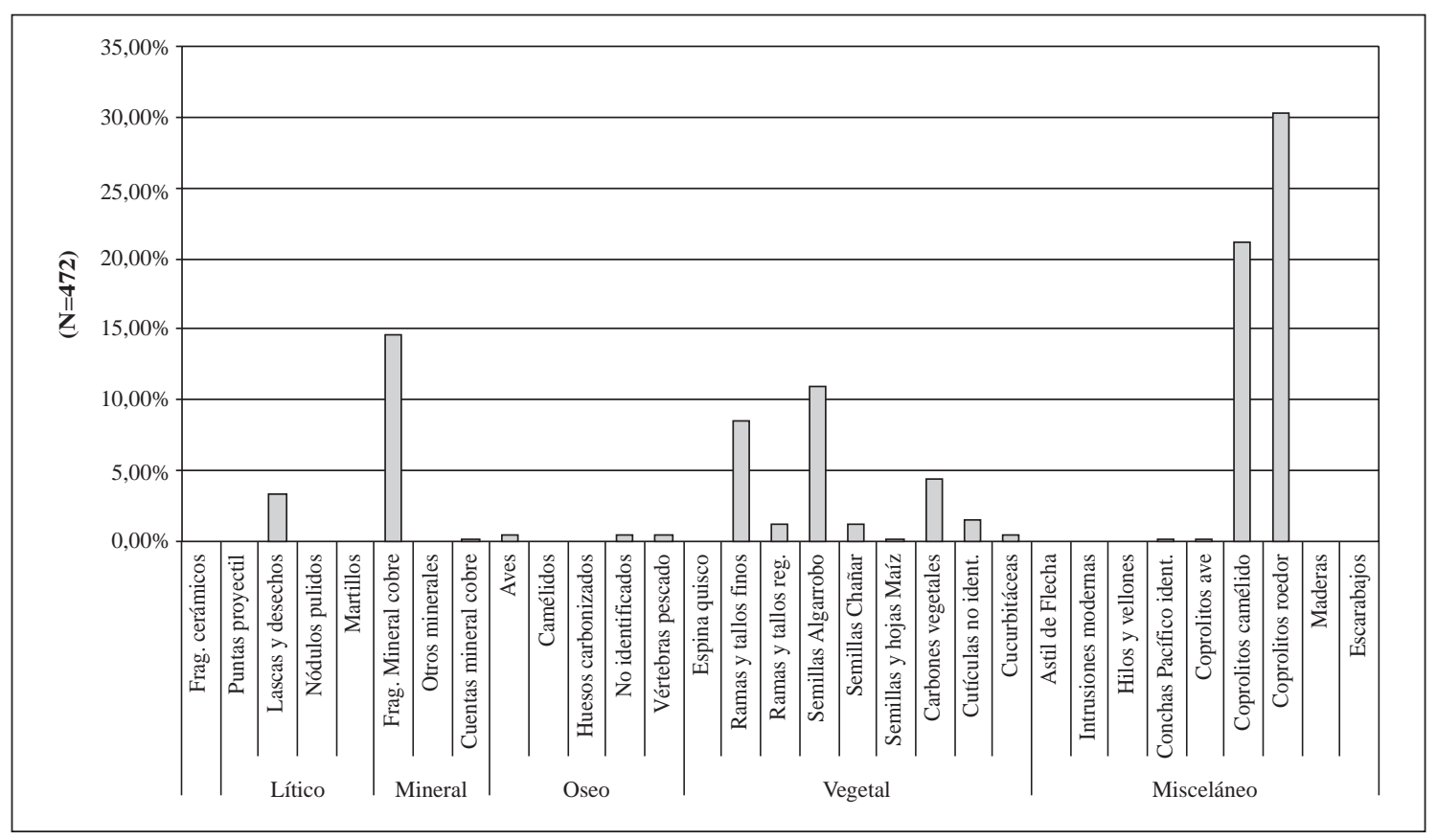

Gráfico 6. Recinto 6: Frecuencias porcentuales de categorías culturales.

\section{Pozo de Sondeo Exterior}

El pozo de sondeo (1 m x $1 \mathrm{~m})$ se ubicó sobre el sector que presentaba la mayor concentración de materiales culturales en superficie (suroeste). Se reconocieron dos estratos: el primero compuesto de un sustrato arenoso mezclado con abundante gravilla y algunos clastos angulosos, de consistencia disgregada y color café grisáceo. Presenta alta concentración de materiales culturales, consistentes principalmente en fragmentos cerámicos y desechos líticos y, en menor medida, coprolitos de camélido y fragmentos de mineral de cobre. Cabe destacar que la concentración de material cerámico y lítico en este pozo es mayor que en cualquiera de las estructuras excavadas, teniendo presente que el depósito alcanzó un promedio de $8 \mathrm{~cm}$ de profundidad.

El estrato 2, culturalmente estéril, se compone de un sustrato con alta proporción de sedimentos limo-arcillosos, mezclados con arena y gravilla angulosa, de consistencia muy compactada y estructura laminar, de color café amarillento. El registro de abundantes fecas de camélidos indicaría que éstos se localizaban fuera de los recintos asociados a labores domésticas, a juzgar por la alta presencia relativa de fragmentos de cerámica, en especial del tipo Sequitor (Gráfico 7).
Como se desprende de los resultados de estas pruebas, es evidente que ninguna de las estructuras tiene ocupaciones densas, aunque sí persistentes. En el interior de éstas se habrían realizado actividades de preparación y consumo de alimentos, descanso y calefacción, siendo los fogones limpiados hacia el exterior de los recintos. Los fogones fueron playos, generalmente sin realizar mayores intervenciones para su creación y, a juzgar por la fuerte actividad eólica, con pocas posibilidades de ser usados de manera estable. La cantidad de materiales culturales es significativa, lo que sugiere su uso esporádico durante el ciclo anual, aunque de manera persistente e intermitente en el tiempo.

Además, hubo escasa preparación de artefactos líticos y abundante machacado de minerales de cobre a juzgar por la alta frecuencia de atacamita en la superficie e interior de los recintos excavados, asociados a martillos de basalto y granito, comunes en la superficie y depósitos (Figura 8). Este registro de cobre al interior de los recintos también pudo incrementarse por el efecto de ráfagas sobre partículas finas localizadas en el entorno del sitio, dado que hubo intensa actividad de molienda fuera de las estructuras. 


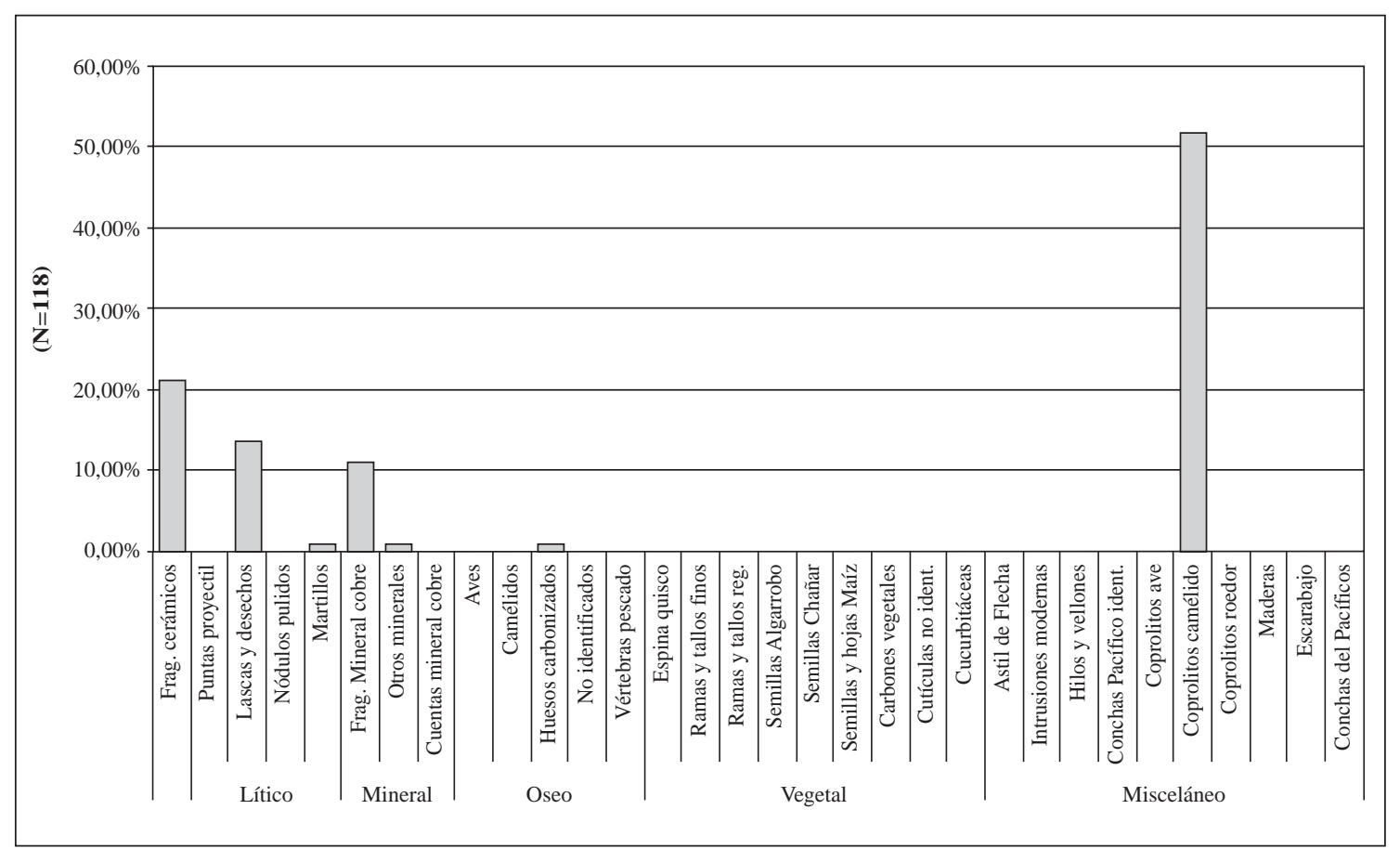

Gráfico 7. Pozo exterior: Frecuencias porcentuales de categorías culturales.

\section{Materiales recuperados de las pruebas estratigráficas}

Aunque los depósitos no son profundos, se registraron 4.318 unidades clasificables, provenientes de las ocupaciones intermitentes entre el Formativo Tardío (Fase Sequitor) y el Período Intermedio Tardío, a juzgar los indicadores cerámicos de superficie. La única determinación $\mathrm{C}^{14}$ (Recinto 3) del orden de los 780 DC (no calibrada) confirma su situación cronológica entre los períodos Formativo Tardío e Intermedio Tardío (Figura 6).

Entre los materiales recuperados, los coprolitos de camélido tienen la más alta representación (21.77\%) acorde a su asociación a la ruta adyacente, y prueban el importante rol de las caravanas de llamas cargueras en torno al traslado e intercambio de productos de consumo humano y animal, incluyendo en este caso cargas preferentes de mineral de cobre en sus recorridos entre paskanas y campamentos (Gráfico 8, Figura 9). Su presencia al interior de los recintos no implica necesariamente que éstos fueran corrales, ya que de acuerdo a la evidencia etnográfica el uso de estructuras para llamas no es indispensable. A los caravaneros les basta un rodeo con manos hasta formar un piño quieto que forrajea y descansa echado junto a los recintos de las paskanas (Leqoc 1987; Nielsen 1997 b y 2001 b; Núñez y Briones 1996 Ms). Más bien, la presencia de fecas al interior de los recintos se relacionaría con la preparación de fogones, dada sus propiedades combustibles.

La alta frecuencia de mineral de cobre molido (16.56\%) demuestra de un modo inequívoco la función más dominante del sitio, es decir, el machacado de minerales de cobre, en su fase previa al fundido, ratificándose la hipótesis derivada del estudio superficial del sitio. Las muestras, tanto superficiales como de los depósitos excavados, corresponden a atacamita, con partículas finas inferiores a $1 \mathrm{~cm}$ de diámetro, producto de prácticas de triturado. Esta selección y chancado de minerales facilita y optimiza las labores de fundición extralocal llevadas a cabo en áreas con suficientes recursos vegetales aptos para combustión. En escasa proporción se advierten fragmentos de azurita y mayormente de crisocola, usados para la elaboración de objetos de uso ritual y ornamental, como las cuentas de collar recuperadas en el sitio. Aunque existen afloramientos en el relieve alto en torno a Chuquicamata (Sergio Rojas, geólogo RT, com. pers. 2001) no se reconocieron artefactos de turquesa celeste (Figura 10). 


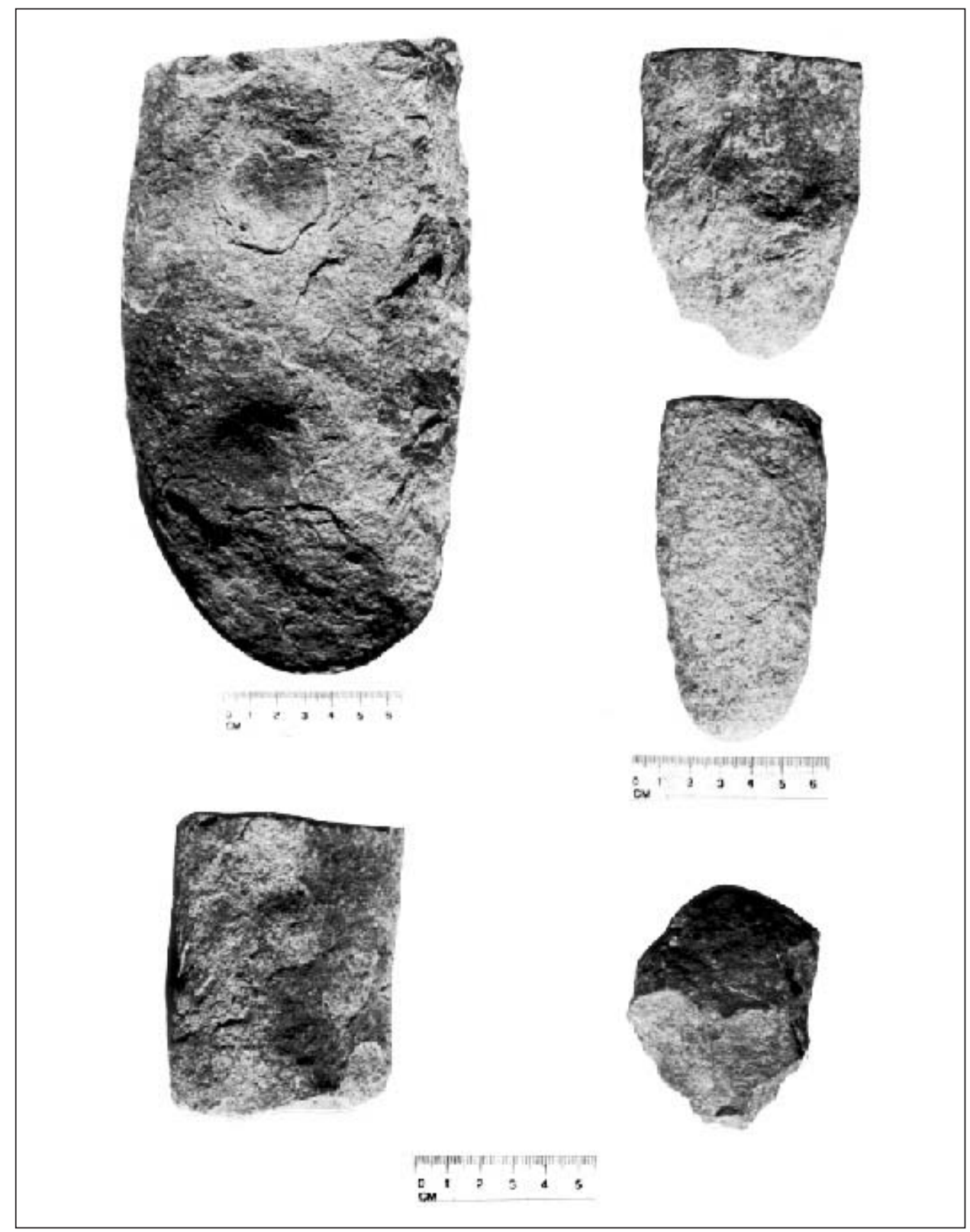

Figura 8. Distintas clases de martillos localizados en el sector extramuros.

Se constató que en el entorno de Chu-2 hay vetas superficiales altamente mineralizadas, explicándose que la locación del campamento se debe a su cercanía a los recursos expuestos. Al igual que los pirquineros modernos, los ocupantes de Chu-2 debieron horadar socavones estrechos, para introducirse en la veta, separando la atacamita de la ganga estéril. Cuando entre la atacamita aparecía la llamativa crisocola, esta era separada de su encajadura estéril con técnicas de martillado, sacándola de la matriz de cuarzo que colabora con la formación de la crisocola, lo que explica el registro de sus desechos. Por otra parte, no está claro si los restos de cuarzo también se juntaban con los minerales de cobre para ayudar a bajar el punto de fusión (Sergio Rojas, geólogo RT, com. pers. 2001). Lo mismo pudo ocurrir con el registro de travertino (carbonato de calcio) y biotita, presentes en el sitio. 


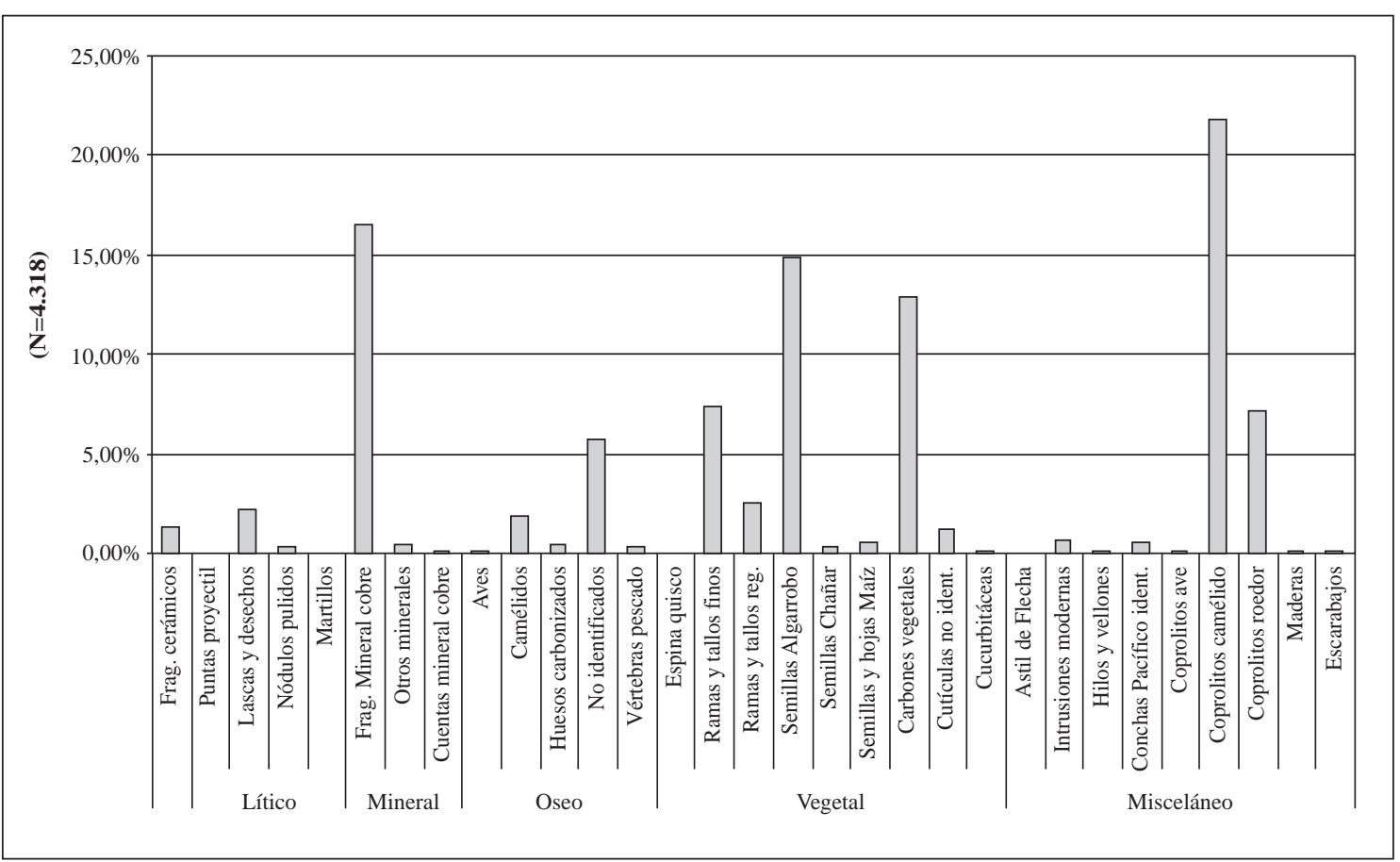

Gráfico 8. Chu-2: Frecuencias porcentuales de categorías culturales para todo el sitio.

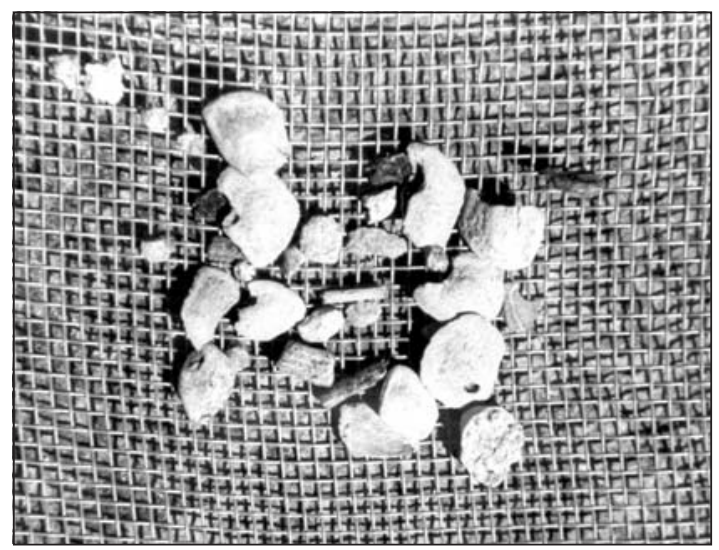

Figura 9. Detalle de coprolitos de camélido, semillas de algarrobo y trozos de carbón vegetal.

Las semillas y restos mínimos de vainas de algarrobo (Prosopis sp.) tienen la tercera mayor popularidad (14.68\%) y su presencia respondería al uso para consumo humano y forraje de las llamas caravaneras. De acuerdo a comparaciones realizadas con muestras actuales de Quillagua y del río Loa Medio (Calama), las semillas provenientes de Chu-2 parecen acercarse más a los especímenes del curso medio, de carácter menos sucu-

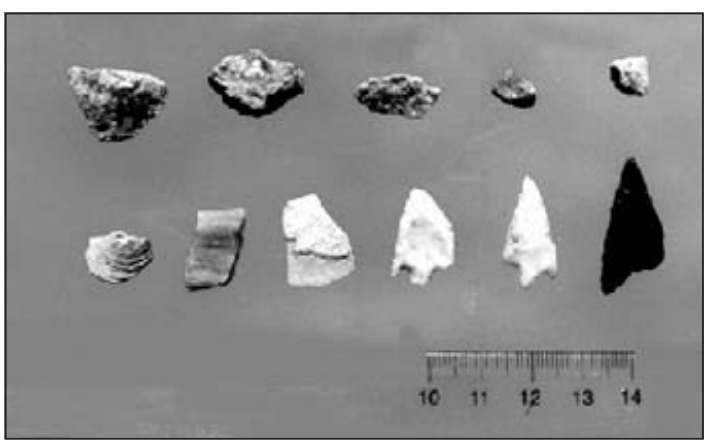

Figura 10. Fragmentos de mineral de cobre, restos de conchas del Pacífico y puntas pedunculadas.

lento y menor tamaño que los primeros (Figura 11). En este sentido, los caravaneros que pernoctaban en los campamentos de labor cargaban en los oasis los productos vinculados con la subsistencia y forrajeo de las recuas donde el algarrobo era más consumido que el chañar (Geoffrea decorticans).

Por otra parte, las ramas y leños carbonizados fueron usados en la preparación de fogones de uso doméstico, al interior de los recintos, demostrándose que esta actividad se vincularía con la preparación de alimentos en el campamento. Asi- 


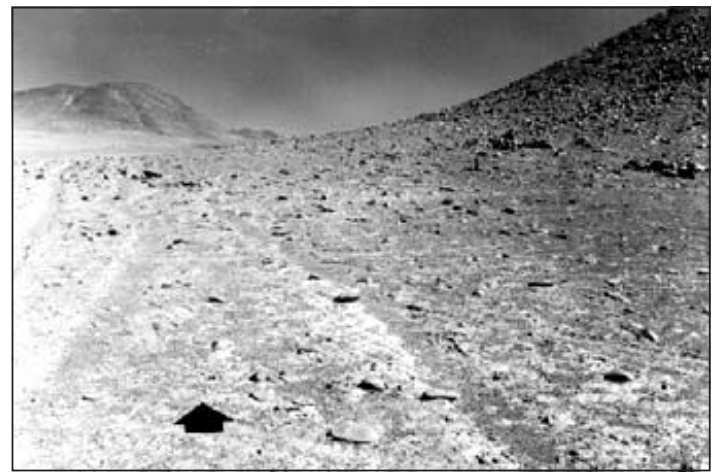

Figura 11. Panorama del campamento Chu-2 asociado a la ruta caravanera (indicada con la flecha).

mismo, la alta frecuencia relativa de ramas, tallos y leños finos $(7.41 \%)$ y más regulares $(2.50 \%)$, dan cuenta del traslado de combustible vegetal desde el Loa Medio, situándose los materiales más cercanos de esta naturaleza, en la Aguada y Salar de Cere. La mayor abundancia de ramas finas y secas se vincularía a la operación del encendido del fuego a partir de yesqueros. El registro etnográfico indica que el uso de chamiza, o ramas secas y finas, es fundamental para el inicio de los fogones, incluyendo después ramas más gruesas y fecas de llamas trasladadas para este efecto a los pisos de los recintos.

Aunque su fragmentación es pequeña, principalmente en forma de astillas, los huesos no identificados $(5.72 \%)$ indican con seguridad su rol en la preparación y consumo de alimentos dentro del campamento.

Con una popularidad un poco mayor a la anterior, las fecas de roedores $(7.16 \%)$ señalan su introducción en los pisos residenciales cuando éstos eran temporalmente abandonados, al igual que el registro de escarabajos y lentes de sedimentos eólicos estériles, lo que implica que el sitio no tuvo una ocupación permanente durante el ciclo anual, esto es, acorde a las instalaciones temporales de las colonias mineras-extractivas y el consecuente cambio de turnos de los trabajadores especializados.

Algo más de 100 líticos (2.57\%) dan cuenta de la escasa preparación de artefactos, a través del registro de desecho de piezas de percusión sobre rocas locales, salvo algunas intrusiones de obsidiana seleccionada desde la alta puna. No es común identificar artefactos de corte, raspado, perforación, ni lascas con filos vivos. Sin embargo, la presencia de martillos líticos en la superficie del sitio, principalmente en espacios externos de labor, y la altísima evidencia de cobre machacado, señalan inequívocamente que el sitio estaba orientado a prácticas mineras especializadas en donde los artefactos líticos de subsistencia no eran tan necesarios.

Lascas y desechos de calcedonia provenientes del río Loa indican que por allí accedían los grupos caravaneros. Por otro lado, la presencia de obsidiana, la cual sólo se ubica en las tierras altas del Loa y San Pedro de Atacama, indica importantes contactos a través de la prolongación de estas rutas hacia espacios altoandinos, vinculados con el registro de cerámica altiplánica.

Aunque en una proporción menor (1.92\%), los huesos de camélido sugieren el consumo de llamas in situ, práctica coherente con la experticia de los ocupantes del sitio en el manejo de recuas de llamas cargueras. Estas presas podrían corresponder a animales caravaneros desechados por edad y/o accidentados, los que no parecen haber sido faenados en Chu-2 (los restos de huesos quemados confirman el carácter alimentario del registro), sino trasladadas desde sus asentamientos estables.

Con una representación algo menor a los huesos de camélidos, la fragmentería cerámica $(1.37 \%)$ es fundamental, en tanto da cuenta del uso de pucos y cántaros de agua en el campamento, en las rutas y al interior de recintos, incluyendo otros espacios intermedios de labor en el entorno de las estructuras. La ausencia de alfarería inca, hispánica y etnográfica sostiene el carácter preincaico del sitio. El comienzo de uso de los recintos ocurrió durante la Fase Sequitor, a partir del 400 DC y a juzgar por la cerámica homónima y por Quillagua Café Amarillenta (QTC), fechada por los 600 a 700 DC vinculada con poblaciones de las cuencas del Salar de Atacama y del Loa, y de Tarapacá respectivamente (Agüero et al. 2001; Ayala y Uribe 2003). La ocupación se habría intensificado con rutas más activas, durante las Fases Quitor y Coyo del Período Medio (400-900 DC) y durante el Intermedio Tardío (900-1450 DC), de acuerdo a la cerámica Dupont (DUP), Turi Gris Alisado (TGA), Aiquina (AIQ), Turi Rojo Alisado (TRA) y Turi Rojo Revestido (TRR), de las cuencas del Loa y Salar de Atacama. 
A base de los indicadores cerámicos se propone que la primera ocupación en Chu-2 ocurrió con mineros-caravaneros de los oasis de San Pedro de Atacama y cuenca del Loa, intensificándose luego con grupos procedentes del Loa Superior y Medio desde los 900 DC. Cuando esto ocurrió, se introdujeron gentes o bienes muy comunes en el Altiplano Meridional y tierras altas del Loa (p.e., Toconce, Lípez), con pucos Hedionda, ampliándose las redes de interacción entre el Loa Medio Superior, la costa y el altiplano aledaño. También se han hallado restos mínimos de plantas y cutículas aún no identificadas, posiblemente correspondientes a vainas, granos, tallos y plantas acuáticas.

Con una representación notablemente inferior (menos de 25 unidades), existen otros registros de importancia a juzgar por su rol desempeñado al interior de los recintos. Entre estos se cuenta el maíz (Zea maiz), presente en hojas o chalas muy fragmentadas $(0.53 \%)$, que podrían significar prácticas de forrajeo, aunque granos y mazorcas son restos de alimentación humana trasladados. A estos se suman los frutos de chañar $(0.28 \%)$ y cucurbitáceas (Cucurbita pepo y/o Cucurbita moschata) (0.16\%).

Igualmente se identificaron con cierta regularidad conchas del Pacífico $(0.60 \%)$ y vértebras de pescados $(0.32 \%)$, que establecen evidencias del acceso al litoral aledaño. Entre estas, se identificaron restos mayoritariamente de Choro mytilus, Oliva peruviana y Semele, es decir, con un uso orientado a alimentos y a la confección de cuentas de collar. Las vértebras de pescado corresponderían a especies de tamaño comparable a jureles, cojinovas o corvinas, es decir, de volumen considerable y con fines alimentarios.

La presencia de conchas del Pacífico en las rutas caravaneras del área de estudio son relativamente comunes. Es claro que estas vías se conectan con la quebrada de Chug Chug, asociada a recursos de agua, y de allí se orientan hacia Quillagua (Figura 10). Desde aquí a la costa la conexión se ha observado a través de rutas caravaneras que continúan hasta la costa de la boca del Loa, con varios campamentos y paskanas intermedias asociadas a cerámica asignable desde fases formativas a inmediatamente preincaicas e inca (Núñez y Briones 1996 Ms).
La más baja representación de los huesos y fecas de aves $(0.16 \%$ y $0.07 \%$, respectivamente) sugiere en el primer caso el traslado de presas al campamento, más que su cacería en el ámbito hiperárido en que se emplaza el sitio. Por otra parte, las fecas de aves guardarían relación con los eventos de abandono parcial del sitio. El registro de puntas pedunculadas para flechas y un astil precisamente da cuenta de probables actividades de caza ocurridas en los valles y costa aledaña.

Los escasos hilos y vellones $(0.12 \%)$ se interpretan como desechos de costales de carga y/o ropas de labor, similares a las que usó el "Hombre de Cobre": taparrabo y una túnica muy gruesa (Bird 1977 y 1979).

Los pocos restos de madera gruesa de prosopis podrían ser parte del enmangado de herramientas de trabajo, tales como palas y cuñas, dada la dureza y resistencia de los leños provenientes de los bosques del Loa Medio.

Aunque poco representadas, las cuentas de crisocola indican que se aplicaron técnicas para separarla de la atacamita durante el machacado, dadas sus propiedades físicas y cromáticas, altamente valoradas para la confección de adornos y aplicaciones en objetos rituales.

Los martillos $(0.02 \%)$ más livianos que aquellos del "Hombre de Cobre" (Bird 1977 y 1979) son más comunes en los sectores exteriores a los recintos, pero también se asocian al machacado y triturado de atacamita. De acuerdo a Latcham (1938) se han identificado grandes martillos de machacado en San Bartolo, Quillagua y Chuquicamata, y recuerda de paso a otro documentado por Boman (1908) para Chuquicamata, todos ellos similares a los usados antes de los incas por el "Hombre del Cobre" (Bird 1977 y 1979). Sin embargo, en Chu-2 no se identificaron los grandes martillos usados en el área de extracción. El tamaño menor aquí se debe a que las técnicas de "separación" de estéril no requiere de martillos muy pesados. Durante épocas coloniales y posteriores del siglo XIX, bajo iguales funciones, se utilizaron martillos pesados de fierro (combos) con mangos cortos para desprender las gangas o encajadura de la roca exterior que envuelve la atacamita. 
Entre los materiales intrusivos y modernos, recuperados de la superficie y de los primeros centímetros de algunos recintos, la presencia de corchetes metálicos, papel, un cuesco de aceituna y restos de cartón, indican que los recintos recibieron ocupaciones muy esporádicas durante el siglo $\mathrm{XX}$, a raíz de las exploraciones y mensuras mineras.

\section{Consideraciones cronológicas}

Sólo dos sitios vinculados con actividades mineras prehispánicas se han datado en el área. Precisamente, la colección "Hombre de Cobre" que debió formar parte de un campamento extractivo fue fechada con una muestra textil $(1350 \pm 80 \mathrm{AP}$ y $1659 \pm 130$ AP), y otra, de un resto del mango de madera de un martillo lítico $(840 \pm 150$ AP), mientras que una tercera muestra de tejido huma-

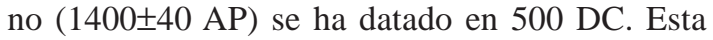
última fecha ha sido considerada la más correcta, y da cuenta de un evento anterior al Período Intermedio Tardío (Bird 1977 y 1979), cuando precisamente ocurrió un auge minero-metalúrgico regional (Núñez 1999). Por otra parte, el otro complejo extractivo relativamente cercano de El Abra, fechado entre los 1300-1475 DC, documenta bien la explotación cuprífera posterior, en un contexto sociopolítico pactado entre la administración inca y la élite atacameña (Núñez 1999).

Para los efectos de cronologizar el campamento Chu-2, Beta Analytic procesó una muestra de carbón del comienzo de ocupación de la Estructura 3 (muestra 4-a/B2), Area de combustión 2 (Figura 5). El resultado corresponde a la datación $\mathrm{C}^{14}$ convencional del orden de los $1110 \pm 60 \mathrm{AP}$, equivalente a cal. 780-1020 DC (cal. 930-1170 Cal. AP), acorde a las estimaciones derivadas del análisis de la cerámica y en sincronía con el conjunto de dataciones $\mathrm{C}^{14}$ del "Hombre de Cobre" (Figura 12).

\section{Conclusiones}

El sitio Chu-2 corresponde al primer campamento minero extractivo preincaico del área, conformado por ocho recintos pircados simples, con actividades intensas intra y extramuros, asociado a rutas caravaneras que lo limitan en su borde suroeste. De acuerdo a sus indicadores cerámicos, estuvo en uso de un modo intermitente desde el Período Formativo Tardío hasta muy cerca de la expansión inca (400-1400 DC). La presencia de

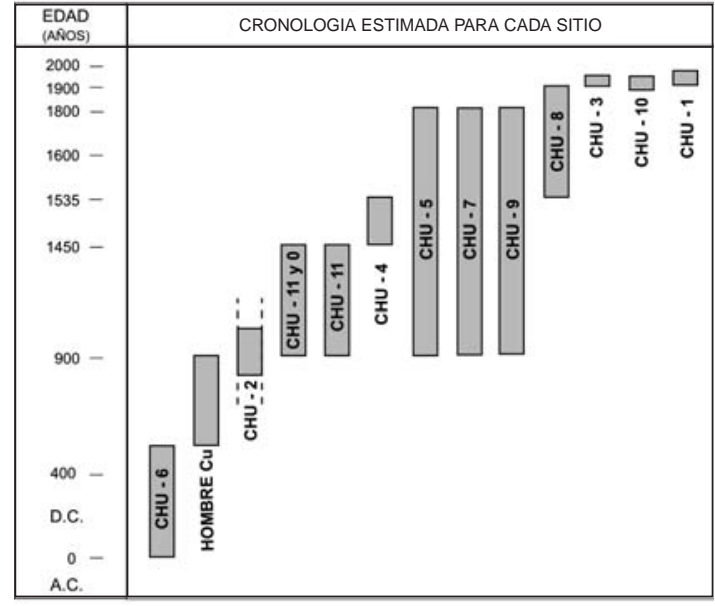

Figura 12. Secuencia de los asentamientos del área minera Chuquicamata-Tomic (basada en $\mathrm{C}^{14}$ ).

lentes con sedimentos eólicos estériles, más la alta frecuencia de coprolitos de roedores, incluso restos de escarabajos y coprolitos de aves, dan cuenta de intervenciones de agentes erosivos y biológicos en las temporadas de ausencia de ocupación. El carácter expuesto del sitio se explica por el énfasis en preparar protecciones pircadas contra el efecto de ráfagas del oeste. Si bien el registro de bajas temperaturas, ráfagas y alta insolación diurna, en estos ambientes altos de cerca de $3.000 \mathrm{~m}$.snm podrían establecerse límites ocupacionales durante el invierno; es posible que el campamento fuera usado todo el año, con más énfasis en las estaciones cálidas. De acuerdo al uso de ropas, el "Hombre de Cobre" sólo muestra una cobertura púbica con faja, como si trabajara bajo condiciones de calor al interior de socavones estrechos. No obstante, Bird (1977 y 1979) comenta el registro de una túnica muy gruesa hallada en Chuquicamata, que apoyaría la idea de mayor abrigo en las faenas, dado el carácter inhóspito del área. Debe tenerse en mente que este minero fue hallado en una mina hoy desaparecida por el socavado del gran rajo abierto localizado a sólo $2 \mathrm{~km}$ al sureste del campamento Chu-2, de modo que no debería descartarse una eventual relación entre ambas evidencias: labor de machacado y socavones de extracción del mineral con uso de los grandes martillos referidos.

La acción de ráfagas y el carácter no continuo de la ocupación habría permitido la depositación de una y dos superposiciones de capas culturales de baja potencia con microestratificaciones, concen- 
tradas en algo menos de $50 \mathrm{~cm}$ de profundidad en ciertos sectores más protegidos, o con un registro más disperso a raíz de los agentes movilizadores naturales. El patrón de depositación a nivel de campamento minero-caravanero no estimuló el desarrollo de depósitos de desechos profundos y continuos sino, camadas horizontales débiles, que incluyen superposiciones lenticulares de cenizas derivadas de labores de cocina al interior del los recintos. El carácter temporal del campamento se advierte en la solución constructiva de poco arraigamiento sin empotración de bloques en el sedimento preexistente. El patrón más común fue la disposición de muros a escasa profundidad, con bloques pesados tomados in situ, para evitar su desplazamiento. Por otro lado, la ausencia de huecos de postes habla a favor de carencia de sombras diurnas bien sustentadas, puesto que sus funciones más importantes ocurrirán en las zonas de descanso y alimentación, aunque no debería descartarse la aplicación de toldos livianos como techos sin constituir un registro arqueológico visible. Las fuerzas de tareas extractivas se concentraron en las vetas aledañas donde pasan gran parte del día, de tal modo que el uso del sitio es de corto tiempo, usualmente vespertino y nocturno; no obstante, otros grupos se dedicaban en el campamento a moler la atacamita traída desde las vetas, sin las gangas ya extraídas fuera del sitio. Aquí se volvería a seleccionar el mineral y se acentuaría el triturado, desechándose los minerales de baja ley, liberando con percutores o martillos más pequeños la encajadura estéril de la crisocola y azurita para extraer aquellos trozos de color intenso. Estas labores se concentrarían fuera de los recintos donde se registran con más frecuencia los restos de martillos. Así, el hallazgo de partículas de atacamita al interior de los recintos podría derivar tanto del machacado como del efecto de ráfagas desde el exterior.

La presencia de escudillas y cántaros de cerámica, además de calabazas para beber, dan cuenta de la preocupación por las actividades de alimentación en un territorio sin recursos cercanos. Tanto así que ramas, frutos de chañar, algarrobos y maíces debieron ser parte de las cargas sin retorno desde los oasis cercanos, con costales adecuados al tráfico caravanero dado el hallazgo de hilos y agujas de cactus.

Es evidente la intensa labor especializada en extracción y selección de atacamita y crisocola (no hay restos de escoria), excluyéndose otras actividades toda vez que los escasos restos líticos son de uso ocasional o expeditivos. De acuerdo a la asociación con las rutas caravaneras de "patrón rastrillo", el desplazamiento por el desierto absoluto ocurre a través de vías que integran artesanías y productos de todo el perfil regional, constatado a través de distintos componentes cerámicos que representan también espacios diferenciados en cotas bajas (Quillagua), medias (Loa Medio) y altas (Loa Superior, Altiplano y San Pedro de Atacama). Por estos sitios se cruzan productos agrícolas y de bosques de oasis: calabazas, zapallos, maíz, algarrobo y chañar. No faltan restos de pescados y mariscos del Pacífico y obsidiana de las tierras altas, del tal modo que, fuera de dudas, las rutas ponen en contacto a gentes y recursos de todo el transecto: Lípez-Loa Superior-cuenca de AtacamaLoa Medio-Inferior-costa, a nivel de mineroscaravaneros. Este modo de explotar tanto recursos mineros como el acceso al litoral es similar a las evidencias de las paskanas asociadas a los geoglifos de Pintados, donde se han identificado, antes de los incas, restos de pescados, maíces y lingotera, en el transecto Pica-costa sur de Iquique (Núñez y Briones $1996 \mathrm{Ms}$ ).

En este sentido el rol de las caravanas fue fundamental para las cargas de minerales, apoyada con forraje trasladado desde los valles (algarrobo, chañar y hoja de maíz). Las llamas se mantenían en el entorno de los recintos, dado a que el hallazgo de abundante fecas al interior de los recintos, desde un punto de vista etnográfico, es funcional con labores de cocina (combustible de alta calidad), calefacción, sumándose cierto ingreso por efecto de ráfagas.

Una vez que las cargas de atacamita y crisocola estaban preparadas, las caravanas salían hacia el río Loa, donde otros especialistas procedían al fundido. Al respecto, se había propuesto que estas tareas ocurrían junto a los recursos boscosos del Loa en términos de combustión de alta calidad (Núñez 1999). Recientes estudios en el marco del Proyecto CODELCO-Nueva Calama han demostrado que en el sector de Topater (borde este de la cuenca de Calama), se sitúa una colina sometida al efecto de ráfaga permanente con pocos restos de ramas, cerámica y crisoles con escoria de cobre adherida, registradas en la cima. Se suman evidencias de escoria, cuentas de crisocola y minerales molidos de atacamita concentrados en 
unos $30 \mathrm{~m}^{2}$ (Núñez $2001 \mathrm{Ms).} \mathrm{Se} \mathrm{postula} \mathrm{que} \mathrm{aquí}$ se habrían instalado guayras, es decir, ingenios de cerámica que captan por sus orificios el viento necesario para mantener el principio de fuelle, sobre fogones, activando el fundido en crisoles. De hecho, la coloración rojiza de los sedimentos de base alterados por alta temperatura permitió localizar el sector del fogón. El registro de cerámica Dupont y otros tipos loínos del Período Intermedio Tardío habla a favor de la contemporaneidad de la "colina de la fundición" de Calama con Chu-2 y otros campamentos del área (Nuñez $2001 \mathrm{Ms}$ ). De un modo similar, restos de hachas metálicas asociadas a escoria habrían sugerido a Latcham (1938) la presencia de guayras u hornillos de fundición en la mina prehispánica de San Bartolo (cercana a San Pedro de Atacama), reactivada recién hacia el año 1848 por la administración Almeida.

El proceso termina con la fundición de cobre y el relleno de las lingoteras o moldes de cerámica y/o piedra. En estos pequeños ingenios fraguaban las barritas que se cargaban en otras caravanas orientadas a territorios carentes de estos recursos. Cada grupo receptor refundía los lingotes para transformarlos en los objetos deseados, mayormente para ornato y rituales, dada la alta jerarquía que significaba portar íconos y emblemas metálicos. Fundiciones en uso durante el siglo XIX se han indicado en las localidades de Yalquincha, Chorrillos y en las "caídas" de Chinchorate a unos $3 \mathrm{~km}$ aguas abajo de Calama, todas asociadas al uso del carbón de leña de los bosques locales de Prosopis, los que, según Phillipi (1860), ya estaban muy agotados a mediados del siglo XIX.

Finalmente, se desprende que el tráfico minero involucró a funciones multipropósito, traslado de recursos y manejo de redes de interacción transectual propios de esta clase de sitios no asociados a hábitats permanentes (Núñez 1984 y 1987; L. R. González 1997; Nielsen 1997a, 1997b y 2001b; Angiorama 2001; Rees y De Souza 2001 Ms). Es así como estos campamentos de labor y las paskanas o estaciones de descanso dejan depósitos culturales con registros exógenos, derivados del traslado de recursos de subsistencia desde las cabeceras aldeanas. Al mismo tiempo, el tipo de evidencia muestra que las ocupaciones son breves -"de paso"-, aunque sostenidas en el tiempo, dando cuenta del "oportunismo" giratorio del tráfico, en términos de aprovechar al máximo todos los recursos altitudinales disponibles. En este caso, se podría plantear que los ocupantes del sitio serían caravaneros-mineros, posiblemente vinculados a redes de interacción mayores. Esto se demostraría por el hallazgo de materiales provenientes de ámbitos ecológicos diferenciados, tales como obsidiana y cerámica Hedionda de las tierras altas, productos vegetales como algarrobo, calabaza, chañar y maíz, de los oasis del pie de la puna e intermedios; conchas y pescados del Pacífico. El "ideal" de complementariedad y traslados transcaravánicos (Murra 1972) y Núñez y Dillehay (1979) fue determinante en el Centro Sur andino, para la instauración de alianzas, armonía social fronteriza y redes de circulación de excedentes de bienes de estatus y domésticos a larga distancia. Estas operaciones se ejecutaban al margen de las demarcaciones territoriales, constituyendo los obrajes mineros la principal labor orientada a la sustentación del régimen señorial de los proto curacas locales, facilitando su inserción en el mundo andino del sur.

Agradecimientos Los autores agradecen la colaboración recibida del personal del Departamento de Medioambiente de la División Radomiro Tomic de CODELCO, en especial de Sandra Riquelme. También queremos agradecer a Mauricio Uribe por realizar la identificación de las colecciones cerámicas.

\section{REFERENCIAS CITADAS}

AGÜERO, C., M. URIBE, P. AYALA y B. CASES, 1997. Variabilidad textil durante el Período Intermedio Tardío en el valle de Quillagua: Una aproximación a la etnicidad. Estudios Atacameños 14: 263-290.

1999. Una aproximación arqueológica a la etnicidad: El rol de los textiles en la construcción de la identidad cul- tural en los cementerios de Quillagua (norte de Chile). Gaceta Arqueológica Andina 25: 167-198.

AgÜERo C., M. URIBE, P. AYAlA, B. CASES y C. CARRASCO, 2001. Ceremonialismo del Período Formativo en Quillagua, Norte Grande de Chile. Boletín de la Sociedad Chilena de Arqueología 32: 24-34. 
ANGIORAMA, C., 2001. De metales, minerales y yacimientos. Contribución al estudio de la metalurgia prehispánica en el extremo noroccidental de Argentina. Estudios Atacameños 21: 63-87.

AYALA, P. y M. URIBE, 2003. La alfarería de Quillagua en el contexto formativo del Norte Grande de Chile. En Actas del XV Congreso Nacional de Arqueología Chilena, en prensa.

BERENGUER, J., 1995. Impacto del caravaneo prehispánico tardío en Santa Bárbara, Alto Loa. En Actas del XIII Congreso Nacional de Arqueología Chilena T II: 185-202, Antofagasta.

BIRD, J., 1977. El hombre de cobre, un minero prehistórico del norte de Chile. Boletín Museo Arqueológico de La Serena 16: 77-106.

-1979. The copper man: A prehistoric miner and his tools from northern Chile. En Precolumbian metallurgy of South America, E. Benson (Ed.), pp. 105-131. Washington D.C.

BOMAN, E., 1908. Antigüedades de la región andina de la República Argentina y del Desierto de Atacama. Universidad Nacional de Jujuy, San Salvador de Jujuy.

BRIONES, L., J. CHACAMA y C. CASTELLON, 1997 Ms. Reciente hallazgo de geoglifos en el norte de Chile, sitio Chug Chug, II Región. Ponencia presentada en el Simposio Internacional de Arte Rupestre, Cochabamba.

CERVELLINO, M. y F. TELLEZ, 1980. Emergencia y desarrollo en una aldea prehispánica de Quillagua-Antofagasta. Contribución Arqueológica 1.

GONZALEZ, A. R., 1979. Precolumbian metallurgy in Argentina: Historical development and cultural process. En Precolumbian metallurgy of South America, E. Benson (Ed.), pp. 133-202. Dumbarton Oaks, Washington D. C.

GONZALEZ, L. R., 1997. Cuerpos ardientes. Interacción surandina y tecnología metalúrgica. Estudios Atacameños 14: $189-210$.

-2001. Tecnología y dinámica social. La producción metalúrgica prehispánica en el Noroeste Argentino. Tesis Doctoral, Facultad de Filosofía y Letras, Universidad de Buenos Aires, Buenos Aires.

LATCHAM, R. 1938. La arqueología de la región atacameña. Prensas de la Universidad de Chile, Santiago.

LECHTMAN, H., 1980. The Central Andes: Metallurgy without iron. En The coming of the Age of Iron, pp. 267-334. Yale University Press, New Haven.

1984. Precolumbian surface metallurgy. Scientific Ameican 250 (6): 38-45.

1997. El bronce arsenical y el Horizonte Medio. En Arqueología, Antropología e Historia en los Andes. Homenaje a M. Rostworowski, R. Varón y J. Flores (Eds.), pp. 153-186. Instituto de Estudios Peruanos, Lima.
LECHTMAN, H. y A. R. GONZALEZ, 1991. Análisis técnico de una campana de bronce de la cultura santamariana, Noroeste Argentino. Boletín del Museo Chileno de Arte Precolombino 5: 81-85.

LECOQ, P., 1987. Caravanes de lamas, sel et échanges dans une communauté de Potosí, en Bolivie. Bulletin de l'Institut Français d'Etudes Andines 16 (3-4): 1-38.

MARCOS, J. y P. NORTON, 1979 Ms. From the yungas at Chinchaysuyo to Cuzco: The rol of La Plata island in Spondylus trade. XLIII International Congress of Americanists, Vancouver.

MURRA, J., 1972. El control vertical de un máximo de pisos ecológicos en la economía de las sociedades andinas. En Visita de la provincia de Leon de Huanuco [1562], J. Murra (Ed.), II, pp. 429-476. Universidad Nacional Hermilio Valdizan, Huánuco.

NIELSEN, A., 1997a. El tráfico caravánico visto desde La Jara. Estudios Atacameños 14: 339-371.

_ 1997b. Tráfico de caravanas en el sur de Bolivia: Observaciones etnográficas e implicancias arqueológicas. Relaciones de la Sociedad Argentina de Antropología XXIIXXIII: 139-178.

- 2001a. Bienes de prestigio en perspectiva histórica: El caso del tráfico de malaquita circumpuneño. En Resúmenes Actas del XIV Congreso Nacional de Arqueología Argentina, pp. 262, Rosario.

_2001b. Ethnoarchaeological perspectives on caravan trade in the South-Central Andes. Ethnoarchaeology of Andean South America. Contributions to Archaeological Method and Theory, L. A. Kuznar (Ed.), pp. 163-201. International Monographs in Prehistory, Ethnoarchaeological Series 4, Ann Arbor, Michigan.

NUÑEZ, L., 1968. Subárea Loa-costa chilena desde Copiapó a Piragua. En Actas del XXXVII Congreso Internacional de Americanistas T II: 145-182, Buenos Aires.

- 1984. Tráfico de complementariedad de recursos entre las Tierras Altas y el Pacífico en el Area Centro Sur andina. Tesis Doctoral, Departamento de Antropología Cultural, Universidad de Tokio, Tokio.

_ 1987. Tráfico de metales en el Area Centro Sur andina: Factos y expectativas. Cuadernos del Instituto Nacional de Antropología 12: 73-105.

_ 1993 Ms. Informe de impacto ambiental arqueológico (Proyecto Kollahuasi). Informe presentado a Geotécnica Ltda.

1994. Emergencia de complejidad y arquitectura jerarquizada en la Puna de Atacama: Las evidencias del sitio Tulán-54. En De costa a selva, M. E. Albeck (Ed.), pp. 85-115. Instituto Interdisciplinario Tilcara, Tilcara.

-1998 Ms. Informe de impacto ambiental arqueológico (Proyecto El Abra). Informe presentado a Geotécnica Ltda. 
- 1999. Valoración minero-metalúrgica circumpuneña: Menas y mineros para el Inka Rey. Estudios Atacameños 18: $177-221$.

_-1999 Ms. Informe de impacto ambiental arqueológico (Proyecto Tomic). Informe presentado a Geotécnica Ltda.

2001 Ms. Informe impacto ambiental arqueológico Proyecto Nueva Calama. CODELCO Chile.

NUÑEZ, L. y L. BRIONES, 1996 Ms. Prospección de la ruta caravanera entre Quillagua y la boca del río Loa.

NUÑEZ L. y T. DILLEHAY, 1979. Movilidad giratoria, armonía social y desarrollo en los Andes Meridionales: Patrones de tráfico e interacción económica. Universidad del Norte, Antofagasta.

PETERSEN, G., 1970. Minería y metalurgia en el Antiguo Perú. Arqueológicas 12, Lima.

PHILLIPPI, J., 1860. Viaje al desierto de Atacama. Librería Eduardo Antón, Halle.

PONCE, C., 1970. Las culturas Wankarani y Chiripa y su relación con Tiwanaku. Los Amigos del Libro, La Paz.

SALAZAR, D., C. JIMENEZ y P. CORRALES, 2001. Minería y metalurgia: Del cosmo a la tierra, de la tierra al Inca. En Tras la huella del Inka en Chile, Museo Chileno de Arte Precolombino, pp. 61-67. Santiago.
SUTUlOV, A., 1978. Chilean mining. CIMM, Santiago.

REES, C. y P. DE SOUZA, 2001 Ms. Procesos de producción lítica durante el Período Formativo de la Subregión del río Salado (II Región, norte de Chile). Ponencia presentada en XV Congreso Nacional de Arqueología Chilena, Arica.

TARRAGO, M. y L. R. GONZALEZ, 1998. La producción metalúrgica prehispánica en el asentamiento de Tilcara (Prov. de Jujuy). Estudios preliminares sobre nuevas evidencias. En Los desarrollos locales y sus territorios. Arqueología del N.O.A, M. B. Cremonte (Comp.), 179-198. Universidad Nacional de Jujuy, San Salvador de Jujuy.

UHLE, M., 1913. Los indios atacameños. Revista Chilena de Historia y Geografía T V: 104-111.

URIBE, M., 1997. La alfarería de Caspana en relación a la prehistoria tardía del desierto de Atacama y su relación con la Subárea Circumpuneña. Estudios Atacameños 14: 243-262.

-1999. La alfarería inca de Caspana (norte de Chile). Boletín de la Sociedad Chilena de Arqueología 27: 11-19.

URIBE, M. y C. CARRASCO, 1999. Tiestos y piedras talladas de Caspana: La producción alfarera y lítica en el Período Tardío en el Loa Superior. Estudios Atacameños 18: 55-71. 